Article

\title{
Acquisition War-Gaming Technique for Acquiring Future Complex Systems: Modeling and Simulation Results for Cost Plus Incentive Fee Contract
}

\author{
Tien M. Nguyen ${ }^{1, *}$, Hien T. Tran ${ }^{2}$, Andy T. Guillen ${ }^{1}$, Tung X. Bui ${ }^{3}$ and Sumner S. Matsunaga ${ }^{1}$ \\ 1 Engineering and Integration Division, The Aerospace Corporation, El Segundo, CA 90245, USA; \\ andy.t.guillen@aero.org (A.T.G.); Sumner.S.Matsunaga@aero.org (S.S.M.) \\ 2 Mathemathics Department, North Carolina State University, Raleigh, NC 27695, USA; tran@ncsu.edu \\ 3 Information Technology Management Department, University of Hawaii at Manoa, Honolulu, HI 96822, \\ USA; tungb@Hawaii.edu \\ * Correspondence: tien.m.nguyen@aero.org
}

Received: 6 November 2017; Accepted: 6 March 2018; Published: 14 March 2018

\begin{abstract}
This paper provides a high-level discussion and propositions of frameworks and models for acquisition strategy of complex systems. In particular, it presents an innovative system engineering approach to model the Department of Defense (DoD) acquisition process and offers several optimization modules including simulation models using game theory and war-gaming concepts. Our frameworks employ Advanced Game-based Mathematical Framework (AGMF) and Unified Game-based Acquisition Framework (UGAF), and related advanced simulation and mathematical models that include a set of War-Gaming Engines (WGEs) implemented in MATLAB statistical optimization models. WGEs are defined as a set of algorithms, characterizing the Program and Technical Baseline (PTB), technology enablers, architectural solutions, contract type, contract parameters and associated incentives, and industry bidding position. As a proof of concept, Aerospace, in collaboration with the North Carolina State University (NCSU) and University of Hawaii (UH), successfully applied and extended the proposed frameworks and decision models to determine the optimum contract parameters and incentives for a Cost Plus Incentive Fee (CPIF) contract. As a result, we can suggest a set of acquisition strategies that ensure the optimization of the PTB.
\end{abstract}

Keywords: game theory; Bayesian games; incentives; contract parameters; Cost plus Incentive Fee (CPIF); mathematical modelling; simulation; program and technical baseline (PTB); acquisition strategy; space systems

\section{Introduction}

The U.S. Department of Defense (DoD) published the Defense Innovation Initiative (DII) with one stated goal to reinvigorate war-gaming capabilities to flesh out more innovative solutions [1]. In addition, DoD and the Air Force updated acquisition regulations and published initiatives to promote the government Owning the Technical Baseline (OTB) and Modular Open System Approach (MOSA) as key enablers for acquisition efficiency and productivity. To address the intent of these initiatives, The Aerospace Corporation has been collaborating with North Carolina State University (NCSU) and University of Hawaii (UH) to investigate and develop an "Acquisition War-Gaming" approach to help advise decisions for acquiring future space systems. The objective is to minimize program execution risks at an affordable cost. Accordingly, our team proposes two innovative frameworks, namely, a Unified Game-based Acquisition Framework (UGAF) and an Advanced Game-based Mathematical Framework (AGMF). The originality of our approach is the innovative 
systematic process for representing a multi-stage, multi-stakeholder acquisition strategy process, and to establish tools that can (i) optimally select the most affordable and least risky Program and Technical Baseline (PTB) solution, (ii) identify the most favorable contract type to acquire the selected PTB solution, and (iii) optimize the contract parameters and incentives for the selected contract type.

Our proposed approach is developed to help the government select a cost-effective acquisition strategy with minimum program execution risks and affordable cost; it is not intended to predict the contractor who will or can win the contract.

We use game theory to address the acquisition process from the government's perspective and the contractors' perspective. The government's perspective is to minimize both risks and costs. The contractors' perspective is to minimize risk of failing the contract terms and conditions and to maximize profit. Using game theory, we assess a combined optimum solution that meets the objectives of both parties. From the government's perspective, affordable cost is assumed when at least two contractors can compete for the government's selected PTB solution. In this paper, we will elaborate on the development of War-Gaming Engines (WGEs) using Bayesian games. The novelty of our approach is not in the application of Bayesian games, but it is in the integration of the war-gaming concept and the Bayesian game theory that results in the development of two distinctive innovations: AGMF and UGAF. The AGMF defines the types of games that meet acquisition objectives of all involved parties, and the UGAF identifies the required solution from the selected games.

This paper provides a high-level summary of the works that the Aerospace team accomplished to date [2-8], and describes how our proposed AGMF-UGAF frameworks and mathematical models can be extended to address the acquisition of a future space system using CPIF contract type.

The UGAF framework $[2,3,8]$ consists of two types of WGEs or game models, namely one representing the government's acquisition perspective, and the other representing the contractor's bidding perspective. The multivariate optimization involves the Defense Acquisition AuthorityWar-Gaming Engine (DAA-WGE) representing the government's objective, and the KTR-WGE representing the contractor's objective. Each WGE is further subdivided into PTB solution models and corresponding Acquisition (A)/Bidding (B) strategy models; government models are abbreviated as DAA-PWGE and DAA-AWGE; contractor models are KTR-PWGE and KTR-BWGE. KTE-BWGE is also referred to as KTR-AWGE because the results of the contractors' bidding games will be used to formulate the government's acquisition strategies. These proposed frameworks and associated game models address technical baseline, contract type, associated incentives, source selection criteria described in Sections M of a Request for Proposal (RFP) [9].

By their very nature, the WGE models employ Bayesian cooperative and non-cooperative games with both complete and incomplete information scenarios. The UGAF dictates what mathematical models (or WGEs) to be used for optimizing the "Acquisition Strategy." The rest of the paper is organized as follows.

Section 2 provides an overview of the acquisition war-gaming concept that lays the foundation for the set-up of the AGMF described in Section 3. In Section 4, we discuss how the UGAF can be used as a process model leading to the optimal acquisition strategy. As contractors are exploring product solutions based on the government's requirements under uncertain market and technological conditions.

Section 5 proposes a gaming strategy that maps various technological and economic scenarios from the perspectives of the contractors and the government. We name these models as PTB-WGEs (abbreviated by PWGEs) as the program technical baseline WGE for the government's (DAA-PWGE) and their counterparts for the contractors (abbreviated by KTR-PWGE).

The gaming process eventually leads to the acquisition and the bidding as the final stage of the acquisition effort. We outline in Section 6 the modeling for the government "Acquisition" DAA-AWGEs and for the contractor "Bidding" KTR-AWGE.

We describe in Section 7 how our framework presented in Section 6 can be extended to CPIF contract and present, as a proof of concept the MATLAB models and simulation results obtained 
from KTR-AWGE model for CPIF. We conclude this paper with some suggestions for future research (Section 8).

To extend our solution to commercial applications, we need to incorporate the required commercial acquisition regulations. It is also worth mentioning that Bargaining Theory [10-12] can be adapted to meet unique FAR regulations from the DOD acquisition context. The Rubinstein's N-person multilateral bargaining model can be tailored to obtain affordable PTB solution and meet the unique FAR regulations for acquiring complex space systems. The key for the tailoring process is to define a set of mapping rules or policies that can (i) map a set of system architecture solutions to a selected set of PTB solutions, (ii) map the selected set of PTB solutions to a unique set of contract type, and (iii) search for an optimum set of incentives and contract parameters that meet FAR requirements. However, this is not the subject of our paper.

\section{Acquisition as a War-Gaming Concept}

From a war-gaming perspective, we view the search for a PTB solution as a step-by-step process of action, reaction, and counteraction for visualizing the execution of each friendly Course-Of-Action (COA) in relation to an adversary's COA and reactions. In war-gaming, planners determine how to apply combat multipliers to the COA to improve the possibility of mission success and minimize risks to soldiers. We incorporate game theory in the "war-gaming" concept to optimize and select: (i) a PTB solution for a given set of warfighter requirements, and (ii) corresponding acquisition strategy and contract incentives for acquiring the selected "PTB solution". The optimization of games requires payoff and cost functions (PCFs) and associated objective function. The players in this acquisition war-gaming are (i) the Government or Defense Acquisition Authority (DAA) and its stakeholders who will provide the system requirements and associate contract terms and requirements in the form of RFP, and (ii) the contractors who are providing their responses in terms of the proposals submission describing their bidding strategies concerning their PTB solutions that meet the specified system performance requirements and contract requirements in terms of cost, schedule and associated incentives. Examples of DAA and its stakeholders are Space Missile Systems Center/Program Executive Officer (SMC/PEO), SMC/Program and Integration (PI) director, SMC/System Program Office (SPO), SMC/Advanced Program (AD) Director, SMC/Contract (PK) Director, SMC/(Engineering (EN) Director. The contractors can be any aerospace company, including, Boeing, Raytheon, Northrop Grumman, Lockheed Martin, Ball Aerospace, L3-Communications, Kratos, etc.

As mentioned above [2,6], we envision two categories of WGEs, namely, Government (or DAA) War-Gaming Engine (DAA-WGE) and Contractor-WGE (KTR-WGE). Figure 1 depicts our vision for the two categories of war-gaming applications [6]. DAA-WGE is to be played by DAA and its stakeholders (see Figure 1a). KTR-WGE is to be played DAA organizations posing as contractors, with game rules dictated by DAA and its stakeholders (see Figure 1b). The DAA-WGE and KTR-WGE mathematical models will be developed and integrated such that DAA and its stakeholders can use them to develop and generate optimum PTB solutions and associated acquisition strategy from both Government's (DAA's) and Contractor's (KTR's) perspective, respectively. The goal is to develop an optimum acquisition strategy that can address optimum contract type, associated incentives with optimum contract parameters and source selection criteria. To achieve this goal, we define and develop the following four types of game models:

- DAA-PWGE: Government plays the game to select optimum PTB solutions. Past acquisition data and market survey data are used to characterize each contractor's bidding behavior. A PTB solution is selected based on minimum program execution risk and cost. From the program execution risk and cost associated with the selected PTB solution, a contract type is selected for the acquisition strategy.

- DAA-AWGE: Government plays the game to optimize acquisition strategy associated with the selected contract type. Past acquisition data and market survey data are used to characterize each 
contractor's bidding behavior. An optimum acquisition strategy is achieved when the selected contract parameters and incentives are optimized for program execution risk and cost.

- KTR-PWGE: In this game, the contractors are simulated as players, and the goal is to select optimum contractors' PTB solutions. Past acquisition data and market survey data are used to characterize each contractor's bidding behavior. A PTB solution is selected for each contractor based on minimum program execution risk and maximum contractor profit. The purpose for this game is not to predict a winner, but to determine if the contractors' solutions are consistent with the Government's solutions. The selected PTB solutions from the contractors' perspective will be used to "shape" the Government's PTB solution to achieve "Affordability" criterion. The "Affordability" condition is achieved when at least two contractors are bidding for the selected Government's PTB solution.

- KTR-BWGE: As mentioned earlier, this game also is referred to as KTR-AWGE because the results of the contractors' bidding games will be used to shape the Government's acquisition strategies. The KTR-AWGE game simulates the contractors as players and the goal is to optimize the contractors' bidding strategies associated with the contractors' selected PTB solution. Past acquisition data and market survey data are used to characterize each contractor's bidding behavior. The optimum bidding strategies are achieved when the selected contract's parameters are optimized based on minimum program execution risk and maximum contractors' profit.

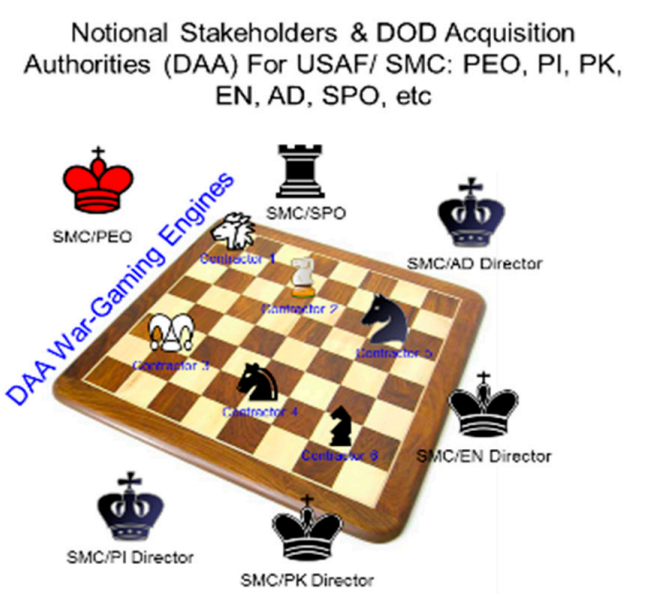

(a)

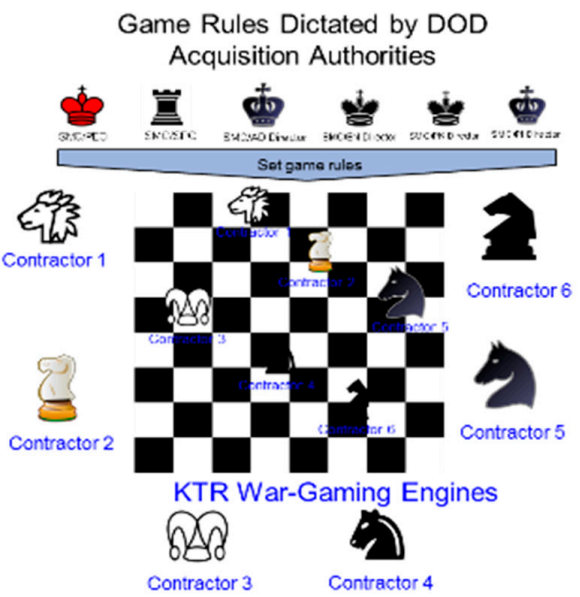

(b)

Figure 1. A Proposed Vision for War-Gaming Applications [3]: War-Gaming Engines to be palyed by (a) Stakeholders \& DoD acquisition Authorities; (b) Contractors (KTRs).

To integrate these WGEs together, The Aerospace's Team develops an advanced mathematical framework (AGMF) and a unified framework (UGAF) that can achieve the vision shown in Figure 1. The proposed unified framework is described in [6,7], which consists of two frameworks, namely, AGMF and UGAF. The AGMF is a framework for selecting optimum game structure and game type depending on the information available for PTB Action Space (PAS) and Acquisition Action Space (AAS). On the other hand, UGAF is for "Exercising" AGMF to generate optimum PTB solutions and optimum acquisition strategies. The detailed discussion of these frameworks can be found in $[2-5,10-12]$, and an overview will be provided in the following sections.

\section{Advanced Game-Based Mathematical Framework (AGMF)}

AGMF consists of the Bayesian game structures and seven game types that are described in Figure 2. As shown in Figure 2, the framework starts the game selection by answering a question concerning the player's ability to observe other player actions. The DAA-PWGE and DAA-AWGE always have the static game structure since all the games will be played by the DAA and its 
stakeholders, with contractors as "players" in each game. On the other hand, the KTR-PWGE and KTR-AWGE can have either static game or dynamic game structure. The KTR-PWGE and KTR-AWGE can have a dynamic game structure when the DAA and its stakeholders assume that one contractor can observe other contractor's action when the games are played. For dynamic game structure, the players make move based on the information released from the RFP and the players' ability (or contractor's ability) to observe other players' action through the "intelligent" information gathered on their competitors. A detailed discussion of AGMF is provided in [5].

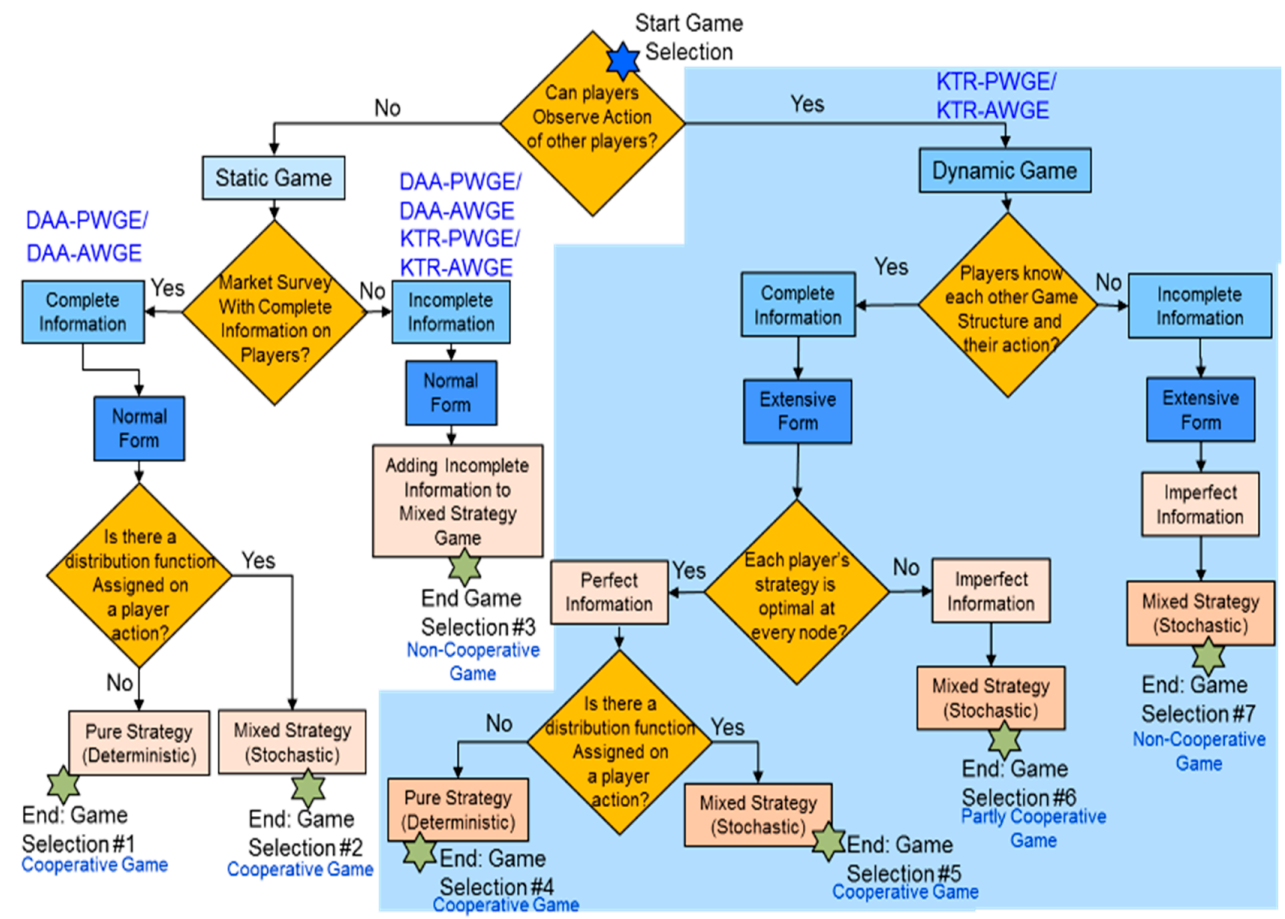

Figure 2. Advanced Game-based Mathematical Framework (AGMF): Selection of Optimum War-Gaming Structure and Type [5].

For the "Static Game," the market survey performed by the Government will be the key in determining the contractor's behaviors. The games will be cooperative, since, in practice, the contractors (KTRs) do cooperate as they should with the Government (DAA) and provide complete information (may be perfect or imperfect) related to the government's requests. Therefore, "End Game Selection \#2" is a cooperative game. On the other hand, the games will be non-cooperative when the contractors are not fully cooperated with the DAA by not providing the information intentionally or un-intentionally. Also, in practice, the contractors do not share information when they are competing against each other, hence the contractors' games for the "Static" case are always non-cooperative under incomplete information. Thus, the "End Game Selection \#3" is a non-cooperative game.

For the "Dynamic Game," the information related to the bidding strategies among the contractors will be the key in the determination of the contractor behaviors. In practice, there are cases that the contractors work together to pre-define the shares of the pie and share the information about their bidding strategies to ensure that they achieve their pre-defined "Sharing Objective." The sharing information may be perfect or imperfect (intentional or un-intentional) among the contractors. Hence, "End Game Selection \#6" is partly cooperative with imperfect information. In practice, there are many instances that the contractors do not cooperate and share the information about their bidding strategies, therefore "End Game Selection \#7" will be selected for this scenario.

It is worth mentioning that the "End Game Selection \#4" may have no pure strategy because the "Uncertainty" associated with the contractors' behaviors at every node of the game. Theoretically, 
one can assume that using past data and deep learning, one can accurately predict the contractors' behaviors with Probability 1. This assumption is used for the completeness of our proposed AGMF.

For "Static Game Structure", the government or DAA and its stakeholders can play DAA-PWGE and DAA-AWGE under government's perspective, i.e., minimizing the execution risk and cost, with the contractors' (players') behaviors characterized by the DAA's "Market Research Results". In practice, due to the high cost associated with the "Market Survey Research" conducted by DAA, it is a "Static" process, meaning the research is usually conducted only one time per program. Unless the program gets delayed for a long-time and research results are out dated, then the DAA might perform a second market survey. This is the key reason DAA only plays "Static Games." It is noted that, currently, our team is investigating advanced approaches to improve the characterization of contractors' behaviors using past data, deep learning, supervised/unsupervised learning, and artificial intelligence.

\section{Unified Game-Based Acquisition Framework (UGAF)}

The goal for UAGF is three-fold, namely (i) play games to determine optimum PTB solution (see Boxes 2, 3 and 4) for a specified set of warfighter needs (Box 1), (ii) identify the optimum contract type for acquiring the selected PTB solution (see Boxes 8 and 9), and (iii) play games to optimize the selected contract parameters and incentives (see Boxes 5,6 and 7) [6]. The optimum PTB solution is defined as the "Architecture Solution" (ARCS) for the required warfighter needs that meets the affordability and expected "Innovative" solution with minimum program execution risk. Note that architecture solution (or ARCS) is described in terms of a set of selected "Technology Enablers" (TEs) that can provide the required system capabilities, which meet the warfighter needs. Where, TE is a specific technology solution that meets a "capability" alone or in combination with other TEs, e.g., a telemetry communications system. Figure 3 describes our proposed unified framework to exercise the AGMF. It describes the processing flow for the DAA-PWGE, DAA-AWGE, KTR-PWGE and KTR-AWGE to generate optimum PTB solutions, optimum contract type and associated optimum contract parameters. Figure 3 also shows the processing boxes, in the order of execution. Detailed description of Boxes \#1 through \#7 are described in [6].

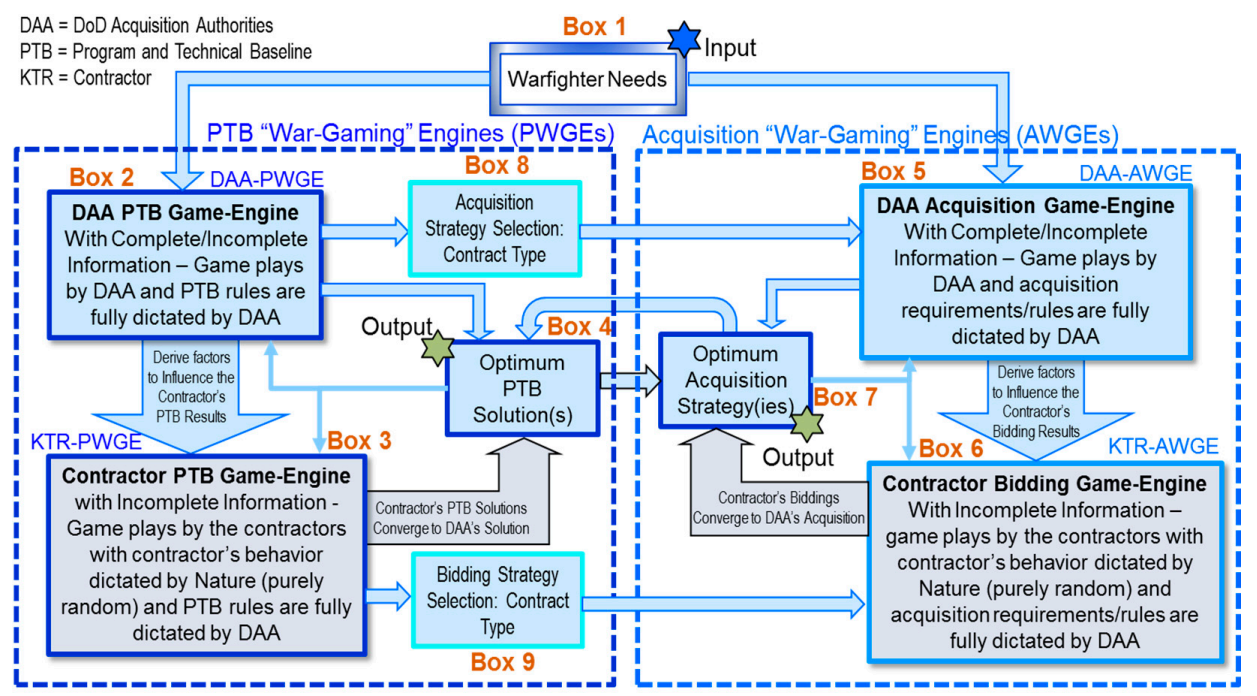

Figure 3. Unified Game-based Acquisition Framework (UGAF): A Unified Approach for Exercising AGMF [6].

\section{PTB War-Gaming Engine (PWGE) Models}

We provide in this section an overview of the Government PTB models (or DAA-PWGE) and contractor PTB models (or KTR-PWGE) [6]. The PTB models discussed in this section focuses on static 
Bayesian game models with "Pure" and "Mixed" games depending on the outcomes of the market survey results. For a pure game with complete and perfect information, the contractors are "surer" of their risk assessments on the selected Technology Enablers (TEs). The risk is either "Good" or "Bad" with probability of 1 and the "Belief" and/or "Weighting" functions for this game type are not needed. For mixed games with complete and imperfect information, the contractors are "more uncertain" of their risk assessments on TEs and the "Belief" and/or "Weighting" functions are needed for assessing TE risks. In this case, the TEs are weighted based on their priorities and using a probability density function with either uniform or triangular distribution depending on the TE's uncertainty.

The TE's uncertainties are expressed in terms of technology and market uncertainties. The definition for the system requirement types and associated PTB solution framework for classifying a PTB Solution are described in Figure 4 [6]. As an example, a Type 1 Requirement is mapped into a "Less Innovative and Conservative PTB Solution" where the "Market Uncertainty" and "Technology Uncertainty" are "Low" and "Low," respectively. Since each "Requirement Type" is associated with specific measure of technology and market uncertainties, the proposed PTB solution framework allows us to select the appropriate acquisition strategy for each "Requirement Type" and assess the technology and cost risk for each "PTB Solution Type."

\begin{tabular}{|c|c|}
\hline $\begin{array}{c}\text { Requirement } \\
\text { Type }\end{array}$ & $\begin{array}{c}\text { Requirement Type } \\
\text { Description }\end{array}$ \\
\hline Type 1 & $\begin{array}{l}\text { Firmed and fixed requirements with } \\
\text { known Technology Enablers and } \\
\text { known market }\end{array}$ \\
\hline Type 2 & $\begin{array}{l}\text { Well-defined requirements with } \\
\text { some uncertainties on technology } \\
\text { enabler and market. Note that firm } \\
\text { Requirements with unknown } \\
\text { market is classified as this Type } 2\end{array}$ \\
\hline Type 3 & $\begin{array}{l}\text { Requirements are somewhat known } \\
\text { with some market uncertainty but } \\
\text { can not identify the exact } \\
\text { technology enablers }\end{array}$ \\
\hline Type 1 & $\begin{array}{l}\text { Requirements are somewhat known } \\
\text { with some technology uncertainty } \\
\text { but can not identify the exact } \\
\text { company (or companies) to provide } \\
\text { the technology enabler }\end{array}$ \\
\hline Type 5 & $\begin{array}{l}\text { Unknown Requirements with } \\
\text { unkhown technology enable and } \\
\text { market }\end{array}$ \\
\hline
\end{tabular}

PTB Solution Framework: PTB Classification based on Requirement Type

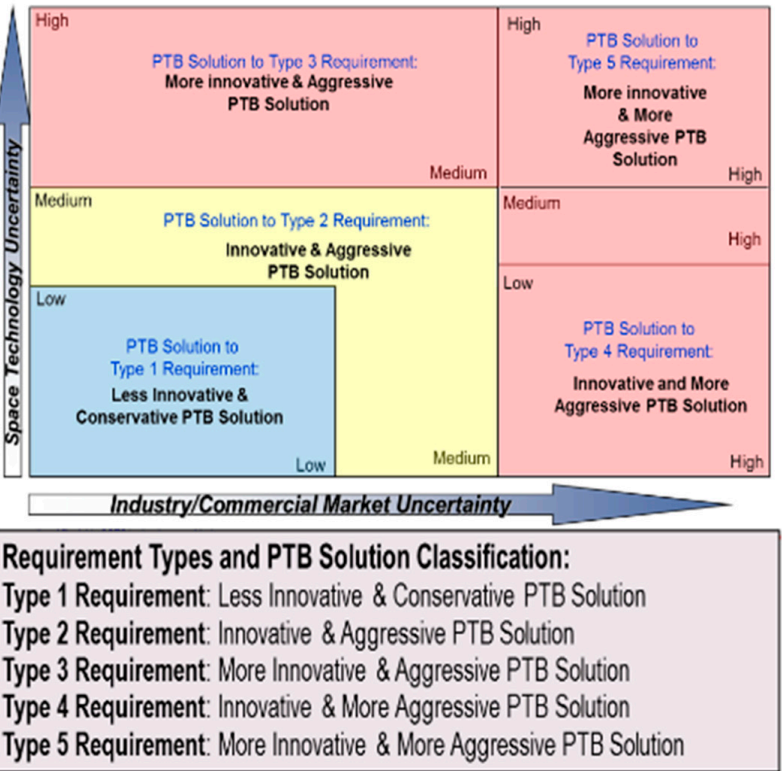

Figure 4. Program and Technical Baseline (PTB) Solution Framework for Classifying PTB Solution Per Requirement Uncertainties [6].

Figure 5 provides a PTB mapping framework to identify the "Acquisition Strategy" or "Contract Type" and risks associated with each "Requirement Type" presented in Figure 4 and "PTB Solution" Type. As shown in Figure 5, the "PTB Solution" Type ranges from "conservative" to "most-innovative." Based on the market and risk uncertainties, Figure 5 also shows the mapping of these uncertainties into "technical and performance risks" and "cost and schedule risks." The following sections describe the PTB models that can be used to search for an optimum PTB solutions under Government's and contractor's perspectives. A detailed description of PTB System Engineering (SE) frameworks, the analytical and simulation modelling approaches for developing optimum PTB solutions can be found in [6,7]. In this paper, we focus on the "PTB Solution Type 3" where the "technical and performance risk" and "cost and schedule risk" are "High" and "Medium," respectively. The "Acquisition Strategy Mapping" for this Type 3 solution is the CPIF contract type. 


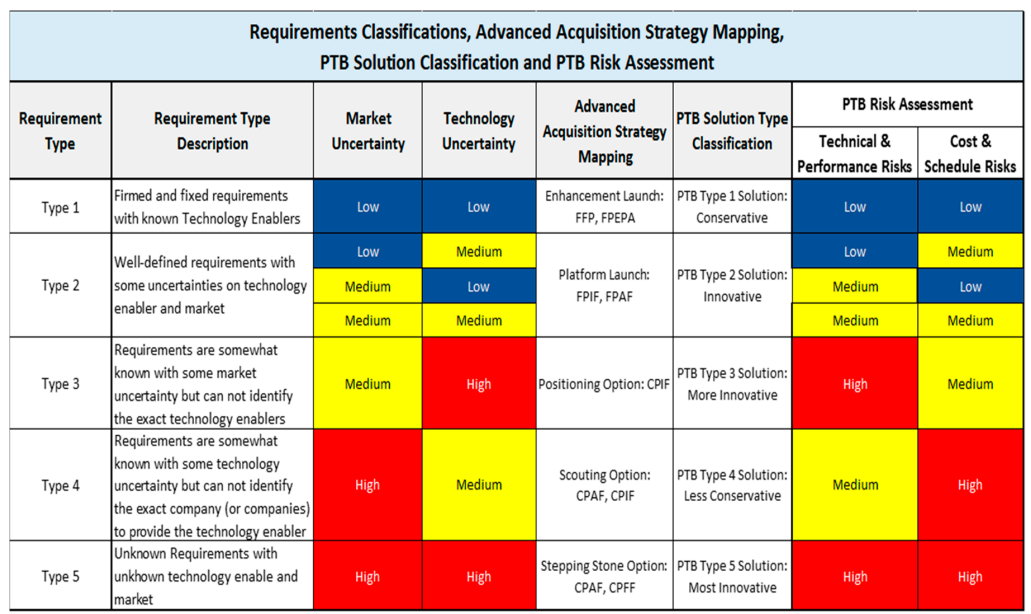

Figure 5. PTB Mapping Framework: Requirement Type-Acquisition Strategy Mapping [6,7].

\subsection{Game Models for Government's PTB}

Currently, our team has developed the mathematical and simulation modelling models for PTB cooperative and non-cooperative Bayesian games for complete information with pure and mixed strategies under both Government's and contractor's perspectives [6]. This section provides an overview description of these models.

DAA-PWGE Cooperative Bayesian Games Set-Up for Complete Information with Pure and Mixed Strategies from Government's Perspective

The DAA plays static Bayesian cooperative games with either complete and perfect information (Pure Game) or complete and imperfect-information (Mixed Game) using normal-form representation of the Bayesian games [6,7]. Our game models assume " $N$ " suppliers (or contractors (KTRs)) participating in the bidding games and the availability of market survey data for which Government's "Request for Information" (RFI) is used to collect the required data from each contractor for assessing potential TEs identified by DAA. The contractor set is defined mathematically as:

$$
K T R=\left\{K T R_{n}, n=1,2, \ldots, N\right\}
$$

The DAA defines PTB strategies involving potential architecture solutions and make them available to each supplier through RFI. The DAA estimates payoff received by each supplier for each combination of PTB strategies that could be chosen by the suppliers. The potential "I" architecture solutions set or ARCS is defined mathematically as:

$$
A R C S=\left\{A R C S_{i}, i=1,2, \ldots, I\right\}
$$

The DAA plays Complete-Bayesian game with a "Pure" or "Mixed" strategy, depending on the market survey data, to select the optimum PTB solution that can achieve "Nash" Equilibrium. "Pure" game will be played if the market survey data show "complete and perfect information" for TEs. On the other hand, "Mixed" game will be played when the data show "complete and imperfect information." A "Pure" Strategy, $S_{\text {Pure }}$, is a strategy for a contractor " $k$ " to map an architecture solution " $i$ " to a PTB solution " $j$ " defined as:

$$
S_{\text {Pure }}=\left\{S_{i, j}^{k}: A R C S_{i}^{k} \rightarrow P T B_{j}^{k} ; i=1,2, \ldots, I ; j=1,2,3,4,5 ; k=1,2, \ldots, N\right\}
$$

A "Mixed" Strategy, $S_{\text {Mixed }}$, is a strategy for a contractor " $k$ " to map an architecture solution " $i$ " to a PTB solution " $j$ " with a "Belief" function $P_{i, j}^{k}$ defined as: 


$$
S_{\text {Mixed }}=\left\{S_{i, j}^{k}: A R C S_{i}^{k} \stackrel{P_{i, j}^{k}}{\rightarrow} \mathrm{PTB}_{j}^{k} ; i=1,2, \ldots I ; j=1,2,3,4,5 ; k=1,2, \ldots, N\right\}
$$

The "Belief" function set or "Conditional" probability set $P$ is defined as "the probability of selecting a PTB solution type " $j$ " given an architecture solution " $i$ ":

$$
P=\left\{P_{i, j}^{k} ; i=1,2, \ldots I ; j=1,2,3,4,5 ; k=1,2, \ldots, N\right\}
$$

The "Belief" function $P_{i, j}^{k}$ must satisfy the following conditions:

$$
0 \leq P_{i, j}^{k} \leq 1 \text { and } \sum_{i=1}^{I} P_{i, j}^{k}=1
$$

Note that the ARCS-PTB mapping rules are based on the "Requirement Type" that is given in Figure 5. The PTB "Utility" set for a "Pure Strategy", $U_{\text {Pure, }}$, is defined as the PCF for selecting a pure strategy $S_{i}^{k}$ for each contractor " $k$," which can be expressed mathematically as:

$$
U_{\text {Pure }}=\left\{U_{i, j}^{k}: S_{i, j}^{k} \rightarrow P C F_{i, j}^{k} ; i=1,2, \ldots I ; j=1,2,3,4,5 ; k=1,2, \ldots, N\right\}
$$

Similarly, the PTB “Utility" set for a "Mixed" strategy, $U_{\text {Mixed }}$, is defined as the PCF for selecting a mixed strategy $S_{i, j}^{k}$ for each contractor " $k$ " with a "Belief" function $P_{i, j}^{k}$ defined as follow:

$$
U_{\text {Mixed }}=\left\{U_{i, j}^{k}: S_{i, j}^{k} \stackrel{P_{i, j}^{k}}{\rightarrow} P C F_{i, j}^{k} ; i=1,2, \ldots, I ; j=1,2,3,4,5 ; k=1,2, \ldots, N\right\}
$$

A notional description of PCF, $P C F_{i, j}^{k}$, and PCF scoring approach is provided in [7]. Note that [7] describes the PCF scoring approach based on seven DOD initiatives, including Initiative (i): "Proposed Technical Requirements and Associated TEs Incorporated Industry's Input"; Initiative (ii): "Should Cost Data Available for Each TE"; Initiative (iii): "Should Cost Data Available for Overall System"; Initiative (iv): "Leverage DOD IRAD to Lower Cost"; Initiative (v): "Leverage Contractor's IRAD to Lower Cost"; Initiative (vi): "Provide Incentives to Allow Contractor to Make IRAD an Allowable Cost"; and Initiative (vii): "Leverage MOSA for Architecture Design Solution." The higher the PCF score, the better PTB solution is.

DAA-PWGE Cooperative Game Set-Up with Complete Information and Pure Strategy

DAA plays the DAA-PWGE "Pure Strategy" games to "Minimize" the Cost and "Maximize" the Payoff (e.g., performance) for the selected optimum strategy, $S_{\text {Opt }}$. Mathematically, DAA plays the following DAA-PTB "Pure" strategy Bayesian games:

$$
\text { Optimum PTB Solution } \equiv S_{O p t}=\underset{\forall i, j, k}{\operatorname{MinMax}}\left\{u_{i, j}^{k}: S_{i, j}^{k} \rightarrow P C F_{i, j}^{k}\right\}
$$

where $S_{i, j}^{k}$ is defined as in Equation (3) and $U_{i, j}^{k}$ is given by Equation (7). This is the "MinMax" optimization problem to search for $S_{O p t}$ such that:

$$
S_{\mathrm{Opt}}=\left\{u_{i, 1}^{k}>U_{i, 2}^{k}>U_{i, 3}^{k}>U_{i, 4}^{k}>U_{i, 5}^{k} \text { for } \forall i \text { and } \forall k\right\}
$$

The above optimum solution is said to achieve the Nash Equilibrium, which is a stable solution to this game theoretic problem in which no individual contractor can improve their payoff by a unilateral change in his bidding behavior. The DAA-PWGE pure game simulation algorithm is shown in Figure 6 with details provided in $[3,4]$. 


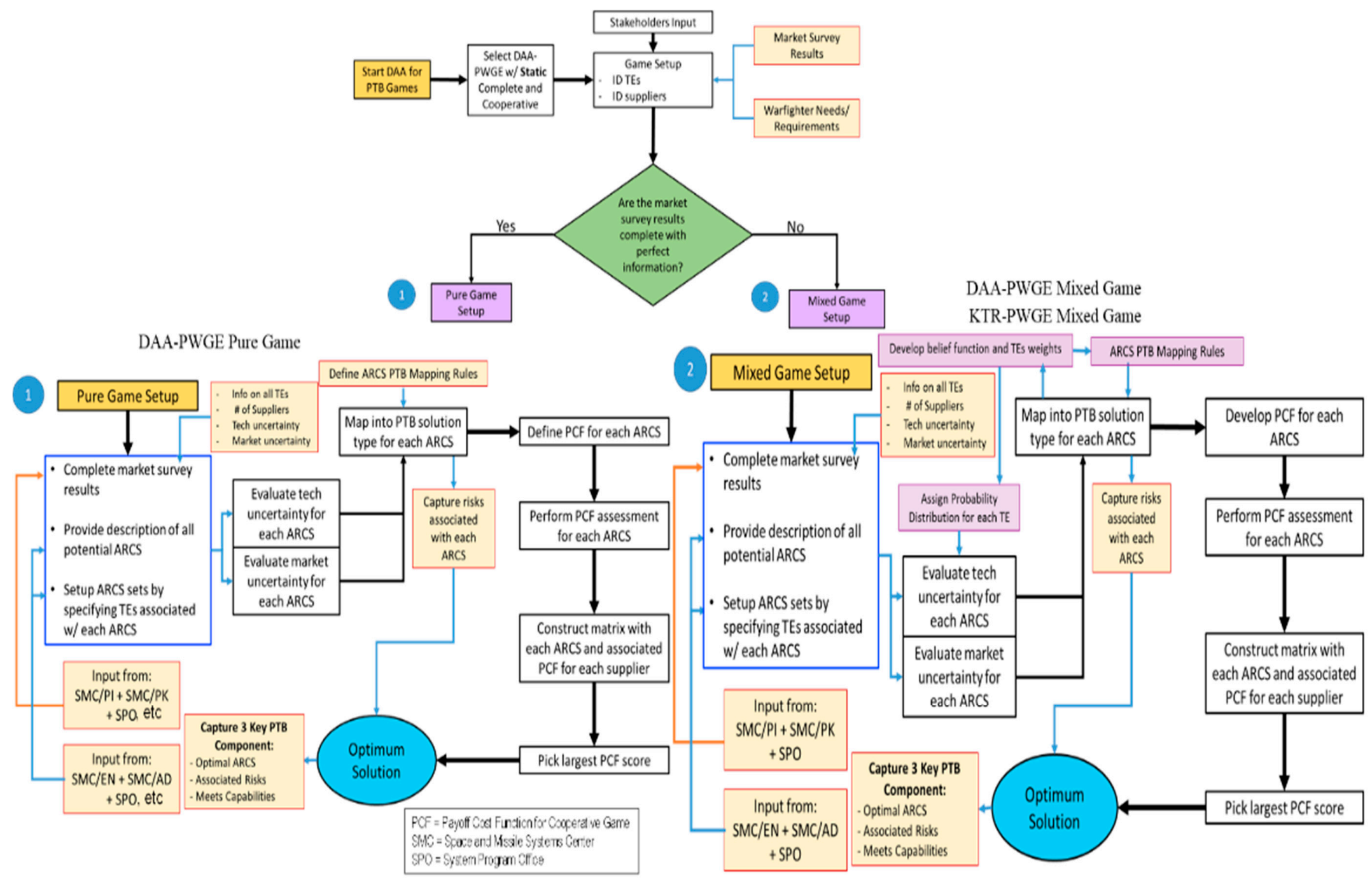

Figure 6. Description of DAA-PWGE and KTR-PWGE Algorithms. 
DAA-PWGE Cooperative Game Set-Up with Complete Information and Mixed Strategy

Like the "Pure" strategy, DAA plays the DAA-PWGE "Mixed Strategy" games to "Minimize" the Cost and "Maximize" the Payoff. Mathematically, DAA plays the following DAA-PTB "Mixed" Strategy Bayesian games:

$$
\text { Optimum PTB Solution } \equiv S_{\text {Opt } t_{\text {Mixed }}}=\underset{\forall i, j, k}{\operatorname{MinMax}}\left\{U_{i, j}^{k}: S_{i, j}^{k} \stackrel{P_{i, j}^{k}}{\rightarrow} P C F_{i, j}^{k} ; i=1, \ldots, I ; j=1, \ldots, 5 ; k=1, \ldots, N\right\}
$$

where $S_{i, j}^{k}$ is defined as in Equation (4), $U_{i, j}^{k}$ is given by Equation (8) and the "Belief" function $P_{i, j}^{k}$ is given by Equation (5). Again, this is the "MinMax" optimization problem that reaches the "Nash Equilibrium" when $S_{O p t_{\text {Mixed }}}$ satisfies the following condition, assuming that $\mathrm{ARCS}_{\mathrm{i}}$ is the optimum solution with PTB Type 1 solution:

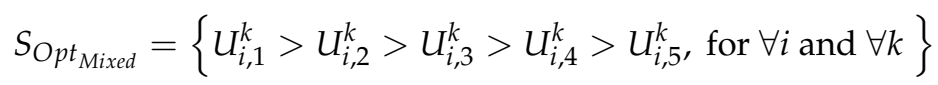

The DAA Plays the DAA-PTB “Mixed Strategy" games to maximize the payoff for the selected optimum strategy $S_{O p t_{\text {Mixed }}}$ resulting from the optimally mapping an "ARCS" to a PTB Solution for

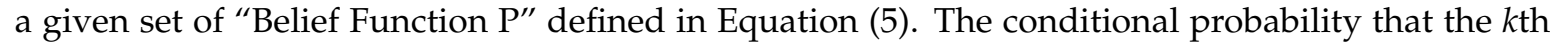
supplier/contractor (KTR) selects the $l$ th TE with a weighting factor of $\mathrm{W}_{l}$ for the ith architecture solution, ARCS ${ }_{i}$, given that the ARCS ${ }_{i}$ is mapped to PTB Type " $j$ ", is defined as:

$$
\operatorname{Pr}_{i, j, l}^{k}=W_{l} \cdot \operatorname{PrTE} E_{i, j, l}^{k}
$$

where

$$
\operatorname{PrTE} E_{i, j, l}^{k}=\operatorname{Pr}\left\{K T R{ }^{\prime \prime} \mathrm{k}^{\prime \prime} \text { Selects } T E_{l}^{k} \text { forARCS }{ }_{i} / K T R^{\prime \prime} \mathrm{k}^{\prime \prime} \text { maps ARCS } \text { to }_{i} \text { PTB Type }{ }^{\prime \prime}{ }^{\prime \prime}\right\}
$$

The "Belief Function" set " $P$ " for all Architecture Solutions, $i=1,2, \ldots, I$, can be calculated using the following equation:

$$
P_{i, j}^{k}=\sum_{l=1}^{L} W_{l} \cdot \operatorname{PrT} E_{i, j, l}^{k}
$$

Note that our team has recently found that the above equation provides a better mathematical model than the one described in [6] for the belief function. Since each TE will have its own "Technology Risk" and "Market Risk", Equation (15) becomes:

$$
\begin{aligned}
P_{1, j}^{k-T e c h} & =\sum_{l=1}^{L} W_{l} \cdot \operatorname{PrTE} E_{i, j, l}^{k-\text { Tech }} \\
P_{1, j}^{k_{1} \text { Market }} & =\sum_{l=1}^{L} W_{l} \cdot \operatorname{PrTE} E_{i, j, l}^{k \_ \text {Market }}
\end{aligned}
$$

$P_{i, j}^{k-T e c h}$ and $P_{i, j}^{k-M a r k e t}$ must satisfy the following conditions:

$$
\begin{gathered}
0 \leq P_{i, \bar{j}}^{k_{-} \text {Tech }} \leq 1 \text { and } \sum_{i=1}^{6} P_{i, \bar{j}}^{k_{-} \text {Tech }}=1, \text { for } \forall k \\
0 \leq P_{i, \bar{j}}^{k_{-} \text {Market }} \leq 1 \text { and } \sum_{i=1}^{6} P_{i, \bar{j}}^{k_{-} \text {Market }}=1 \text {, for } \forall k
\end{gathered}
$$

Note that the terms "Technology Risk/Market Risk" and "Technology Uncertainty/Market Uncertainty" are used interchangeably in this section. A detailed description of the computational approach for the belief function is provided in [6,7]. The DAA-PWGE mixed game algorithm is shown in Figure 6 with the details provided in [6,7]. The computational approach described in [3] should be 
modified as shown in Equation (15). The PTB tracking tool described in $[4,5]$ will be used to capture the PTB solution captured by the DAA-PWGE.

\subsection{Models for Contractor PTB Games}

For KTR-PWGE model, the DAA plays games on behalf of the contractors [6,7]. Like the DAA-PWGE game, the KTR, actually played by DAA, plays the static Bayesian "Non-Cooperative" (NC) games with complete and imperfect information or mixed-game using normal-form representation of the game. The game is NC because it is assumed that the contractors do not share their bidding information. The KTR plays game to select optimum PTB solution that can maximize profits and reduce execution risks. The KTR is assumed to play games to search for an optimum PTB solution that can achieve the "Nash" Equilibrium. The KTR game is set up as follows:

Step 1: Contractor set: Assume to have $\mathrm{N}$ contractors to play the game (see Equation (1)).

- Step 2: Contractor identifies a set of potential "I" architecture solution $A R C S_{N C}$ based on the requirements described in the release of RFI or RFP from a Government agency:

$$
A R C S_{N C}=\left\{A R C S_{N C_{-} i}, n=1,2, \ldots, I\right\}
$$

- Step 3: Each architecture solution selected by a KTR will be mapped into a unique PTB solution type defined by DAA

- $\quad$ Step 4: The Non-Cooperative (NC) game with mixed strategy and incomplete information: The strategy for the $k$ th contractor to map the $i$ th architecture solution to the $j$ th PTB solution type is performed using the following mathematical expression:

$$
S_{\text {Mixed_Non_Coop }}=\left\{S_{N C_{-}, i, j}^{k}: A R C S_{N C_{-} i}^{k} \stackrel{P_{N C}^{k} C_{i, j}}{\longrightarrow} P T B_{N C_{-} j^{\prime}}^{k} ;=1,2, \ldots, I ; j=1,2,3,4,5 ; k=1,2, \ldots, N\right\}
$$

- $\quad$ Step 5: The "Belief Function" set or conditional probability set " $P$ " for NC games: For each contractor " $k$ ", the belief function " $P_{\text {Non-Coop }}$ " is defined as the probability of selecting a PTB solution type " $j$ " given the $i$ th architecture solution:

$$
P_{\text {Non-Coop }}=\left\{P_{N C_{i}, j}^{k} ; i=1,2, \ldots, I ; j=1,2,3,4,5 ; k=1,2, \ldots, N\right\}
$$

where $P_{N C_{i}, j}^{k}$ is defined as:

$$
P_{N C_{i}, j}^{k}=\sum_{l=1}^{L} W_{N C_{l}} \cdot \operatorname{PrTE} E_{N C_{i}, j, l}^{k}=\left\{\begin{array}{c}
P_{N C_{i}, j}^{k_{\text {Tech }}}=\sum_{l=1}^{L} W_{N C_{l}} \cdot \operatorname{PrT} E_{N C_{i}, j, l}^{k_{\text {Tech }}} \\
P_{N C_{i}, j}^{k_{M a r k e t}}=\sum_{l=1}^{L} W_{N C_{l}} \cdot \operatorname{PrTE} E_{N C_{i, j}, l}^{k_{M a r k e t}}
\end{array}\right\}
$$

Like the DAA games, the above equation provides a better mathematical model than the one described in [3] for contractor games, and Equation (22) must also satisfy the following condition:

$$
0 \leq P_{N C_{i}, j}^{k} \leq 1 \text { and } \sum_{i=1}^{I} P_{N C_{i}, j}^{k}=1
$$

- $\quad$ Step 6: PTB Utility Set for a "NC Mixed Strategy" is defined as $U_{\text {Mixed_Non_Coop. This is the }}$ $\mathrm{PCF}_{\mathrm{NC}}$ for selecting a mixed strategy $S_{i, j}^{k}$ for the $k$ th contractor. Mathematical, it is given by the following equation:

$$
U_{\text {Mixed_Non_Coop }}=\left\{U_{N C_{-}, i, j}^{k}: S_{N C_{-} i, j}^{k} \stackrel{P_{N C}^{k} C_{i, j}}{\rightarrow} P C F_{N C_{-}, i, j}^{k} ; i=1,2, \ldots, I ; j=1,2,3,4,5 ; k=1,2, \ldots, N\right\}
$$


- $\quad$ Step 7: The KTR plays the following mixed game to select the optimum PTB solution:

$$
\text { KTR Optimum PTB Solution }=S_{O_{p t} K T R}=\underset{\forall i, j, k}{\operatorname{Max}}\left\{U_{N_{-} C_{-}, j}^{k}: S_{N C_{-} i, j}^{k} \stackrel{P_{N C_{i} i, j}^{k}}{\longrightarrow} P C F_{N C_{-} i, j}^{k}\right\} .
$$

Like the DAA-PWGE game, the contractors will be simulated as players to play KTR-PWGE games to maximize their payoff or "Profit" for the selected optimum strategy $S_{O p t_{K T R}}$ resulting from optimally mapping an "ARCS" to a PTB Solution for a given set of belief function " $P_{\text {Non-Coop." The detailed }}$ KTR-PWGE mixed game algorithm is shown in Figure 6 with details provided in [6,7]. The PTB tracking tool described in $[4,5]$ will be used to capture the PTB solution captured by the KTR-PWGE.

\section{Acquisition-Bidding War-Gaming Engine (AWGE) Models}

The approach for the development of Acquisition-Bidding WGEs presented in this section follows [7]. An overview description of the Government "Acquisition" DAA-AWGEs and contractor "Bidding" KTR-AWGE will be presented in this section. The acquisition-bidding game model assumes that there are $\mathrm{N}$ contractors participating in the bidding of the space system with the contractor set given by Equation (1). The following subsections describe the game setup from the government and contractor perspectives, namely, DAA-AWGE and KTR-AWGE, respectively.

\subsection{Models for Government Acquisition Games—DAA-AWGE Game Set-Up}

The DAA-AWGE model simulates the Government's acquisition games from the Government perspective based on the "Contract Type" selected based on the PTB solution obtained from DAA-PWGE models described in Section 5. The DAA-AWGE strategy is to map the optimum "Type $i$ th PTB Solution" $\left(P T B_{i}\right)$, obtained from DAA-PWGE and KTR-PWGE games described in Section 5 above, to the optimum "Acquisition Strategy" and the associated "Type $i$ th Contract" $\left(C T_{i}\right)$. Denote the Government strategy as $S_{D A A}$, mathematically $S_{D A A}$ for Bayesian games with complete and imperfect information can be written as:

$$
S_{D A A}=\left\{S_{D A A_{i}}: P T B_{i} \stackrel{p_{i}^{D A A}}{\rightarrow} C T_{i} ; i=1,2, \ldots, N\right\}
$$

where $p_{i}^{D A A}$ is the Government "Belief Function" describing the probability that the DAA will map $P T B_{i}$ to $C T_{i}$. It is defined as follows:

$$
P_{D A A}=\left\{p_{i}^{D A A} ; i=1,2, \ldots, N\right\}
$$

Each $p_{i}^{D A A}$ must satisfy the following conditions:

$$
0 \leq p_{i}^{D A A} \leq 1 \text { and } \sum_{i=1}^{N} p_{i}^{D A A}=1
$$

The DAA utility function $U_{D A A}$ is defined as:

$$
U_{D A A}=\left\{U_{D A A_{-} i}: S_{D A A_{i}} \stackrel{p_{i}^{D A A}}{\rightarrow} P C F_{D A A_{i}} ; i=1,2, \ldots, N\right\}
$$

where $P C F_{D A A_{i}}$ is the Government PCF associated with the selection of the ith strategy $S_{D A A_{i}}$. If PCF is the Government estimated "contractor cost" associated with the space system being acquired 
$\left(P C F_{D A A_{-} K T R_{i}}\right)$, the "Nash Strategy" dictates that the optimum strategy for selecting the contract parameters is to minimize the PCF according to:

$$
S_{D A A_{O p t}}=\underset{\forall i}{\operatorname{Min}}\left\{P C F_{D A A_{-} K T R_{i}}\right\}=\underset{\forall i}{\operatorname{Min}}\left\{S_{D A A_{i}} \stackrel{p_{i}^{D A A}}{\rightarrow} P C F_{D A A_{-} K T R_{i}} ; i=1,2, \ldots, N\right\}
$$

If the Government utility function $U_{D A A_{i=1}}$ represents the optimum Government saving strategy expressed in Equation (30), $S_{D A A_{O p t}}$, the following condition must be true according to Nash:

$$
U_{D A A_{-} K T R_{i=1}}=\left\{S_{D A A_{1}} \stackrel{p_{1}^{D A A}}{\rightarrow} P C F_{D A A_{-} K T R_{i=1}}\right\}<U_{D A A_{-} K T R_{i=2}}<U_{D A A_{-} K T R_{i=3}}<\cdots<U_{D A A_{-} K T R_{i=N}}
$$

If PCF is the Government saving associated with the space system being acquired ( $\left.P C F_{D A A_{-} \text {Savingi }}\right)$, "Nash Strategy" dictates that the optimum contract parameters can be selected by maximizing the saving or PCF according to:

$$
S_{D A A_{O p t}}=\underset{\forall i}{\operatorname{Min}}\left\{P C F_{D A A_{-} \text {Saving }_{i}}\right\}=\underset{\forall i}{\operatorname{Max}}\left\{S_{D A A_{i}} \stackrel{p_{i}^{D A A}}{\rightarrow} P C F_{D A A_{-} \text {Saving }_{i}} ; i=1,2, \ldots, N\right\}
$$

If the Government utility function $U_{D A A_{i=1}}$ represents the optimum Government saving strategy expressed in Equation (32), $S_{D A A_{O p t}}$, the following condition must be true according to Nash strategy:

$$
U_{D A A \_ \text {Saving }_{i=1}}=\left\{S_{D A A_{1}} \stackrel{p_{1}^{D A A}}{\rightarrow} P C F_{D A A \_S_{a v i n g}}\right\}>U_{D A A \_ \text {Saving }_{i=2}}>\cdots>U_{D A A \_ \text {Saving }_{i=N}}
$$

The DAA can play non-cooperative or cooperative games depending on the "Contract Type." For example, for the FFP contract type, the DAA plays non-cooperative games if the DAA provides a clear direction on the FFP contract that the lowest bidder will be selected and there is no negotiation between the Government and the selected contractor. On the contrary, the FPIF contract type requires the cooperation between DAA and the selected contractor to agree on a set of sharing ratios (SRs), and perhaps on the Point of Total Assumption (PTA) [13] as well.

\subsection{Models for Contractor Bidding Games_KTR-AWGE Game Set-Up}

The KTR-AWGE model simulates the contractor's bidding games from the contractor perspective based on the "Contract Type" and the associated contract parameters generated from the DAA-AWGE games. Let $b_{i}$ be the bidding strategy for the $i$ th contractor, the contractor strategy set for Bayesian game with complete and imperfect information, $S_{K T R}$, is defined as:

$$
S_{K T R}=\left\{S_{K T R_{i}}: K T R_{i} \stackrel{p_{i}^{K T R}}{\rightarrow} b_{i} ; i=1,2, \ldots, N\right\}
$$

where $p_{i}^{K T R}$ is the conditional probability that the $i$ th contractor selects the $i$ th bidding strategy given by:

$$
\begin{gathered}
P_{\text {KTR }}=\left\{p_{i}^{K T R} ; \forall i\right\} \\
\sum_{i=1}^{n} p_{i}^{K T R}=1
\end{gathered}
$$

The contractor utility function $U_{K T R}$ is defined as:

$$
U_{K T R}=\left\{U_{K T R_{i}}: S_{K T R_{i}} \stackrel{p_{i}^{K T R}}{\rightarrow} P C F_{K T R_{i}} ; i=1,2, \ldots, N\right\}
$$


where $P C F_{K T R_{i}}$ is the contractor PCF associated with the $i$ th contractor, $K T R_{i}$, who selects the $i$ th bidding strategy $S_{D A A_{i}}$. Since the $P C F_{K T R_{i}}$ is the contractor cost associated with the space system being acquired $\left(P C F_{D A A_{-} K T R_{i}}\right)$, "Nash Strategy" dictates that the optimum bidding parameters are selected by maximizing the contractor cost function according to:

$$
S_{K T R_{O p t}}=\underset{\forall i}{\operatorname{Max}}\left\{P C F_{K T R_{i}}\right\}=\underset{\forall i}{\operatorname{Max}}\left\{S_{K T R_{i}} \stackrel{p_{i}^{K T R}}{\rightarrow} P C F_{K T R_{i}} ; i=1,2, \ldots, N\right\}
$$

If the contractor utility function $U_{K T R_{i=1}}$ represents the optimum contractor profit strategy expressed in Equation (38), $S_{K T R_{O p t}}$ the following condition must be true according to Nash strategy:

$$
U_{K T R_{i=1}}=\left\{S_{K T R_{1}} \stackrel{p_{1}^{K T R}}{\rightarrow} P C F_{K T R_{1}}\right\}>U_{K T R_{i=2}}>U_{K T R_{i=3}}>\cdots>U_{K T R_{i=N}}
$$

Note that the KTR-AWGE models always assume non-cooperative games since the contractors do not share their bidding strategies among themselves.

\section{From Bidding to Contracting: Extending AWGE Model to CPIF Contract Type}

This section extends the mathematical models presented in Section 6 to CPIF under the assumption that the PTB solutions obtained from the DAA-PWGE and KTR-PWGE models described in Section 5 above are both "Type 3 PTB Solution" and the corresponding optimum "Contract Type" is CPIF (see Figure 5). Per FAR No. 16.404 and FAR No. 16.302-16.306, CPIF is a cost-reimbursement contract that provides for the initially negotiated fee to be adjusted later by an "Incentive" formula based on the relationship of total allowable costs to total target costs. To be more precise, for a typical CPIF contract, Contractor and Government (or the Government Contracting Officer (GCO) agree on a target cost, a target fee, and an incentive formula for determining the final fee. The formula provides for an adjustment in the fee, based on any difference between the target cost and the total allowable cost of performing the contract. Unlike the Fixed-Price Incentive Firm (FPIF) contract, the contract will provide both a minimum and maximum limit on the fee adjustment.

The CPIF contract parameters include cost and price points, a ratio, and a formula to calculate the fees. The parameters are defined as follow:

- Cost = Actual KTR Production/Service Cost, which is usually "unknown" from one contractor to another and Government (during the pre-award contract phase) $=\mathrm{A}_{C}$

- $\quad$ Fee $=$ KTR Fee

- $\quad$ Price $=$ Cost + Fee

- $\quad$ Funding Limit $=$ Maximum price the government expects to pay

- Target $\operatorname{Cost}\left(\mathrm{T}_{\mathrm{C}}\right)$ : The initially negotiated figure for estimated contract costs and the point at which profit pivots

- $\quad$ Target Fees $\left(\mathrm{T}_{\mathrm{F}}\right)$ : The initially negotiated fees at target cost, i.e., it is the difference between cost and price at target cost

- Share Ratio (SR): The Govt/contractor SR for cost savings or cost overruns that will increase or decrease the actual profit.

- $\quad$ Point of Total Assumption $=\mathrm{PTA} \triangleq$ Pessimistic Cost Estimate $=\mathrm{P}_{\mathrm{C}}$

- $\quad$ Range of Incentive Effectiveness = RIE = The range of cost outcomes over which the contract contemplates the sharing of some "pool of profit"

- $\quad$ Funding Limit $=\mathrm{CP}=$ Equivalent to Ceiling Price in FPIF, which is the Maximum Price that Government is willing to pay

Figures 7 and 8 provide a detailed description of CPIF contract and the relationship among the

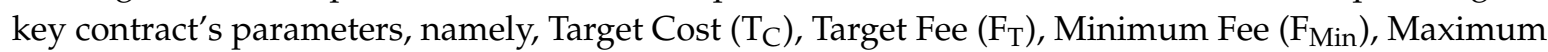


Fee $\left(\mathrm{F}_{\mathrm{Max}}\right)$, SRs, Incentive Fee Adjustment Formula, and Range of Incentive Effectiveness (RIE) and PTA. SRs include Government SR $\left(\mathrm{SR}_{\mathrm{G}}\right)$ and contractor $\mathrm{SR}\left(\mathrm{SR}_{\mathrm{C}}\right)$.

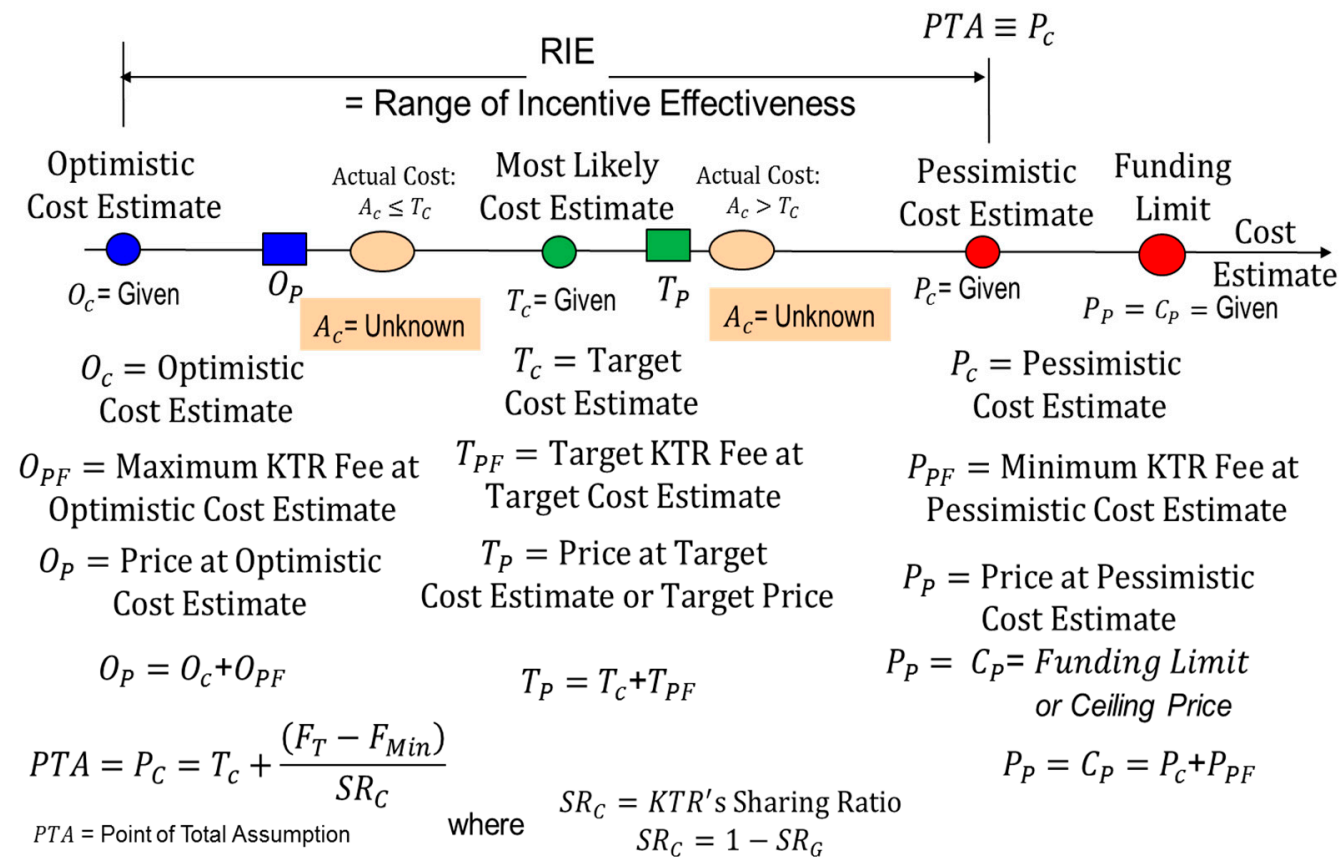

Figure 7. Understanding of Cost Plus Incentive Fee (CPIF) Contract.

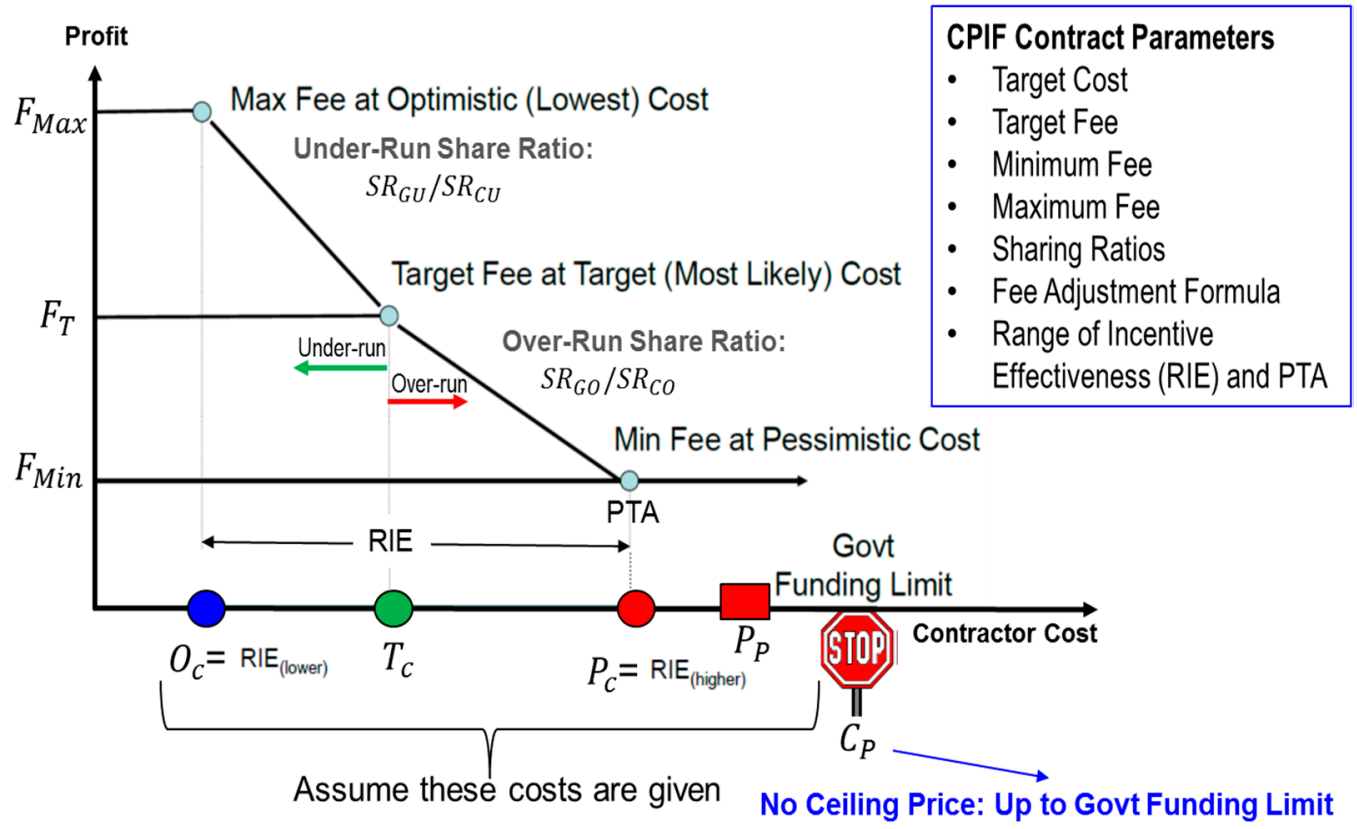

Figure 8. Description of the CPIF Contract's Parameters Relationship.

The goal of this Section is to extend the mathematical Models model presented in Section 6 to search for optimum Target Price, SRs, Target Fee, Minimum Fee and Maximum Fee. 


\subsection{Model for Government Acquisition Game: DAA-AWGE}

The modelling development approach for the DAA-AWGE CPIF contract type is identical to FPIF approach described in [7]. The model assumes that both the Government and the contractor will cooperate to maximize their minimum saving/profit. Therefore, their bargaining objective will be the maximization of the minimum outcome of the saving/profit, i.e., the "maximum" value of the saving/profit. Let $P C F_{G o v}$ and $P C F_{K T R_{i}}$ be the final compromised saving/profit points, and $P C F_{G o v}^{0}$ and $P C F_{K T R_{i}}^{0}$ be the benchmark saving/profit points for the negotiation between the Government and the $i$ th contractor, respectively. The optimum CPIF contract parameters can be obtained by solving the following optimization problem [4]:

$$
\underset{\forall i}{\operatorname{MinMax}}\left\{F_{i}: F_{i}=\left(P C F_{G o v}-P C F_{G o v}^{0}\right) \cdot\left(P C F_{K T R_{i}}-P C F_{K T R_{i}}^{0}\right) ; i=1,2, \ldots, N\right\}
$$

Note that $P C F_{G o v}$ and $P C F_{K T R_{i}}$ are also defined as the Government's "Cost Saving" and the $i$ th contractor profit, respectively, and they are given by [4]:

$$
\begin{gathered}
P C F_{G o v}=C_{p}+S R_{G_{i}}\left(T_{C}-A_{C_{i}}\right)-\left(A_{C_{i}}+P C F_{K T R_{i}}\right) ; i=1,2, \ldots, N \\
P C F_{K T R_{i}}=\left(T_{p_{i}}-T_{c}\right)+S R_{C_{i}} \cdot\left(T_{C}-A_{C_{i}}\right) ; i=1,2, \ldots, N
\end{gathered}
$$

where $C_{p}$ is the Government "Funding Limit," $S R_{G_{i}}$ is the Government sharing ratio and $A_{c_{i}}$ is the actual production cost for the $i$ th contractor, which is unknown and as before, it is assumed to be either uniformly distributed over $\left[O_{c}, P_{c}\right]$, or triangularly distributed over $\left[O_{c}\right.$, $\left.P_{c}\right]$ with mode "m." Substituting $P C F_{K T R_{i}}$ into $P C F_{G o v}$, the Government's "Cost Saving" in terms of the contract parameters can be obtained as:

$$
P C F_{\text {Gov }}=C_{p}+2\left(1-S R_{C_{i}}\right) \cdot\left(T_{c}-A_{C_{i}}\right)-T_{p_{i}} ; \forall i
$$

Substituting Equation (52) into Equation (49), and using the calculus of variation approach, the optimization problem can be solved by searching for the SRs that can maximize $F_{i}$ and then search for the optimum target price $T_{P}$ that can maximize $F_{i}$. For both DAA and KTR games, we first maximize the cost function $F_{i}$ with respect to the contractor sharing ratio, $S R_{C_{i}}$, by solving the following equation:

$$
\frac{\partial F_{i}}{\partial S R_{C_{i}}}=0, \forall i
$$

Note that the contractor sharing ratio ranges from 0 to 1 and the Government sharing ratio for the $i$ th contractor, $S R_{G_{i}}$, is defined as:

$$
S R_{G_{i}}=1-S R_{C_{i}}
$$

For DAA-AWGE game from the DAA perspective, optimality occurs when the partial derivative of $F_{i}$ with respect to the contractor is zero:

$$
\frac{\partial F_{i}}{\partial P C F_{K T R_{i}}}=0, \forall i
$$

Note that for KTR-AWGE game from the contractor perspective, Equation (47) becomes:

$$
\frac{\partial F_{i}}{\partial P C F_{G o v}}=0
$$

Solving Equation (45) and Equation (47), the optimum win-win sharing ratio, $S R_{C_{-} O p t_{i}}$, and optimum win-win target price, $T_{p_{\mathrm{Opt}_{i}},}$ from the DAA perspective are found as follow [4]: 


$$
\begin{aligned}
S R_{C_{-} O p t_{i}} & =\frac{2 P C F_{K T R_{i}}^{0}-P C F_{G o v}^{0}-\left(3 T_{p}-4 T_{C}\right)+\left(C_{p}-2 A_{C_{i}}\right)}{4\left(T_{C}-A_{C_{i}}\right)}, \forall i \\
T_{P_{O p t_{i}}} & =\left(2 A_{C_{i}}-C_{P}\right)+\left[P C F_{G o v}^{0}+2 P C F_{K T R_{i}}^{0}\right] ; i=1,2, \ldots, N
\end{aligned}
$$

For CPIF, the optimum contract parameters depend on whether the contract is the under-run or over-run case. The under-run case occurs when the actual cost of the $i$ th contractor is less than or equal to target cost, i.e., $A_{C_{i}} \leq T_{\mathcal{C}}$. The over-run case occurs when $A_{C_{i}}>T_{\mathcal{C}}$.

- $\quad$ Case 1: Under-run case: $A_{C_{i}} \leq T_{\mathcal{C}}$

For this case, the benchmark saving/profit points for the negotiation between the Government and the $i$ th contractor become:

$$
\begin{gathered}
P C F_{\text {Gov }}^{0}=\alpha_{i}\left(T_{c}-A_{C_{i}}\right) ; \forall i \\
P C F_{K T R_{i}}^{0}=\left(C_{p}-T_{c}\right)
\end{gathered}
$$

where $\alpha_{i}$ is the control parameter that is used to control the contractor's $i$ th profit at the beginning of the Government-Contractor negotiation. $\propto_{i}$ can be used to characterize contractor's behavior. Substituting Equations (51) and (52) into Equations (49) and (50), we obtain the optimum target price, $T_{p_{\text {UOpt }}{ }^{\prime}}$ and the optimum win-win contractor sharing ratio, $S R_{C_{u O p t_{i}}}$ :

$$
\begin{aligned}
T_{p_{\text {UOpt }_{i}}} & =C_{P}-1.5 S R_{C U_{i}} \cdot\left(T_{\mathcal{C}}-A_{C_{i}}\right) ; \forall i \\
S R_{C_{\text {UOpt }}} & =\frac{2(2-\alpha)}{3},\left(\frac{1}{2}\right) \leq \alpha \leq 2 ; \forall i
\end{aligned}
$$

Note that the optimum target price expressed in Equation. Equation (53) indicates the optimum target price that is acceptable to Government when the optimum value of $\alpha, \alpha_{O p t}$, is selected based on the minimum Government payment.

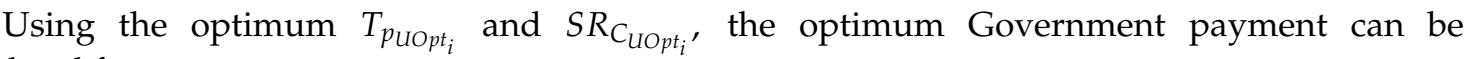
calculated from:

$$
P_{\text {Gov }_{\text {UOpt }} \text { CPIF }}=A_{C_{i}}+\left(T_{p_{\text {UOpt }}}-T_{c}\right)+S R_{C_{\text {UOpt }}} \cdot\left(T_{c}-A_{C_{i}}\right) ; \forall i
$$

The parameter $\alpha_{i}$ in Equation (51) will be selected to minimize the Government payment.

Using the above optimum values for target price and SRs, the optimum Target Fee $\left(F_{T_{-} O p t_{1}}\right)$, Minimum Fee and Maximum Fee can be estimated using the following equations:

$$
\begin{gathered}
F_{T_{-} \_p t_{i}}=T_{p_{{\text {UO } p t_{i}}}-T_{C}} \\
F_{\text {Min_Opt }_{i}}=F_{T_{\mathrm{Opt}_{i}}}-S R_{C_{\text {UOpt }_{i}}}\left(P_{\mathcal{C}}-T_{\mathcal{C}}\right) \\
F_{\text {Max_Opt }_{i}}=S R_{C_{\text {UOpt }_{i}}}\left(T_{\mathcal{C}}-O_{c}\right)+F_{T_{-} O p t_{i}}
\end{gathered}
$$

- $\quad$ Case 2: Over-run case: $A_{C_{i}}>T_{\mathcal{C}}$

For this case, the benchmark saving/profit points for the negotiation between the Government and the $i$ th contractor become:

$$
\begin{gathered}
P C F_{\text {Gov }}^{0}=0 \\
P C F_{K T R_{i}}^{0}=\beta_{i}\left(C_{p}-A_{C_{i}}\right) ; \forall i
\end{gathered}
$$

where $\beta_{i}$ is the control parameter that is used to control the contractor's $i$ th profit at the beginning of the Government-Contractor negotiation. Similarly, $\beta_{i}$ can be used to characterize contractor's behavior for the over-run case. 
Substituting Equations (59) and (60) into Equations (49) and (50) above, we obtain the optimum target price, $T_{p_{\mathrm{OOpt}}}$, and the optimum win-win contractor sharing ratio, $S R_{\mathrm{COOpt}_{i}}$ for the over-run case:

$$
\begin{gathered}
T_{p_{\mathrm{OOpt} i}}=C_{P}-1.5\left(1-S R_{\mathrm{CO}_{i}}\right) \cdot\left(A_{C_{i}}-T_{c}\right) ; \forall i \\
S R_{C_{\mathrm{OO} p t_{i}}}=1-\frac{4}{3} \frac{(1-\beta)\left(C_{P}-A_{C_{i}}\right)}{\left(A_{C_{i}}-T_{c}\right)} \leq \beta \leq 1 ; \forall i
\end{gathered}
$$

This is the optimum target price that the Government is seeking by selecting the optimum value of $\beta$ based on the minimum contractor profit or minimum Government payment.

Using the optimum $T_{p_{\mathrm{OOpt}}}$ and $S R_{\mathrm{COOpt}_{i}}$ the optimum Government payment can be calculated from the following equation:

$$
P_{\text {Gov OOpt }_{\text {CPIF }}}=A_{C_{i}}+\left(T_{p_{O O P t_{i}}}-T_{c}\right)+S R_{C_{O O p t_{i}}} \cdot\left(T_{c}-A_{C_{i}}\right) ; \forall i
$$

The parameter $\beta_{i}$ in Equation (62) will be selected to minimize the Government payment. The optimum target price depends on the maximum funding limit $\left(C_{P}\right)$, contractor sharing ratio, target cost and actual cost of the ith contractor. Figure 9 describes the DAA-AWGE-CPIF Monte Carlo simulation approach to determine the optimum target price, SRs and Government payment under Government's perspective.

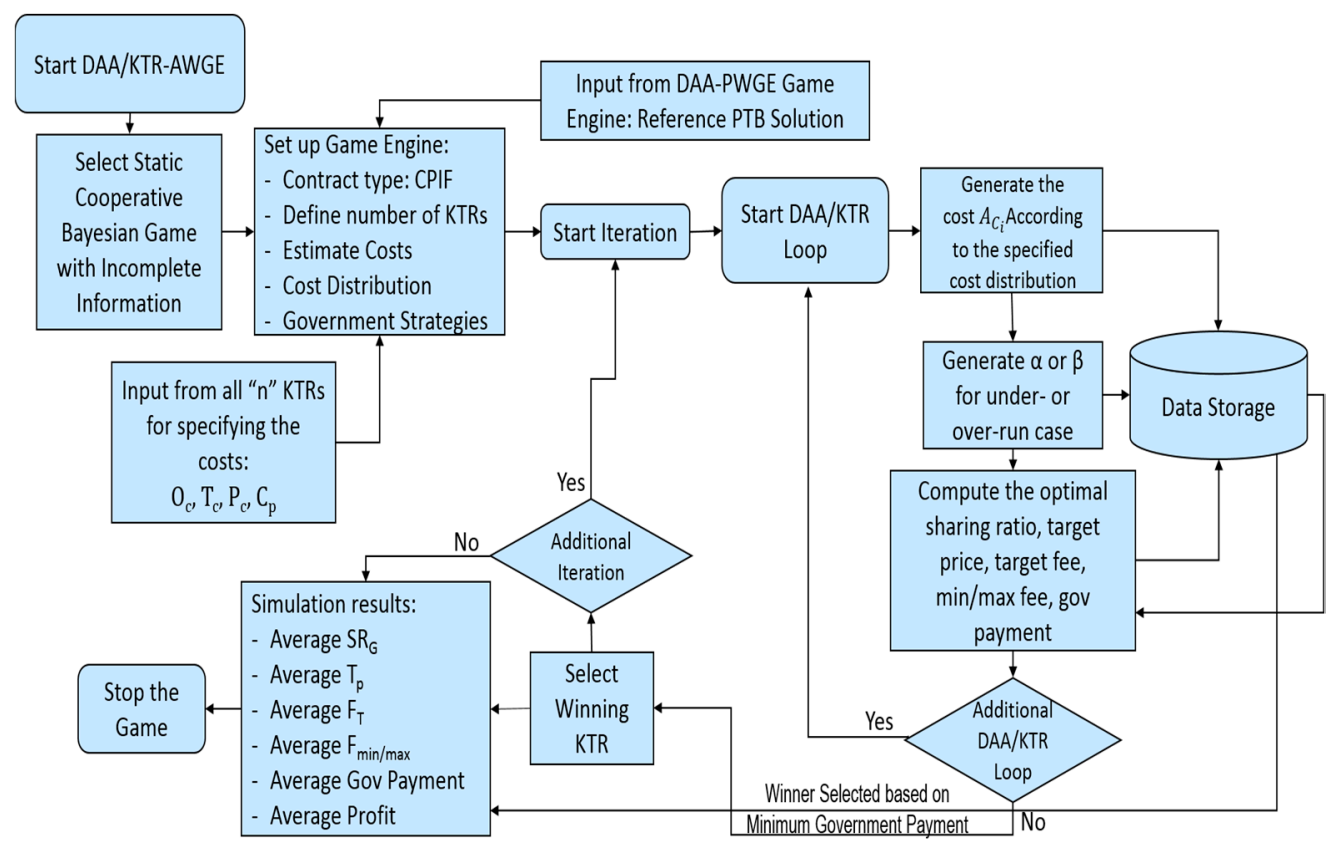

Figure 9. DAA-AWGE Modelling and Simulation Flow Diagram for CPIF Contract Type.

As indicated in Figure 9, the output of the DAA-AWGE CPIF model includes the average optimum values of the target fee $\left(F_{\text {TOpt_ave }}\right)$, minimum fee $\left(F_{\text {minOpt_ave }}\right)$ and maximum fee $\left(F_{\text {maxOpt_ave }}\right)$, assuming there will be $M$ optimum values for all the selected contractors by the end of the games. The calculations of these optimum values are given by the following formulas:

$$
F_{\text {TOpt_ave }}=\sum_{i=1}^{M} \frac{\left(T_{p_{\text {UOpt }}}-T_{C}\right)}{M}
$$




$$
\begin{aligned}
F_{\text {minOpt_ave }} & =\sum_{i=1}^{M} \frac{\left(F_{T O p t \_a v e}-S R_{C_{O O p t_{i}}}\left(P_{c}-T_{c}\right)\right)}{M} \\
F_{\text {maxOpt_ave }} & =\sum_{i=1}^{M} \frac{\left(S R_{C_{\text {UOpt }}}\left(T_{c}-O_{c}\right)+F_{T O p t \_a v e}\right)}{M}
\end{aligned}
$$

where $T_{p_{\text {UOPt }}}, S R_{C_{O O p t_{i}}}$ and $S R_{C_{\text {UOpt }}}$ are defined as above. The estimate costs $O_{c}, T_{c}$ and $P_{c}$ are the optimistic cost estimate, target cost estimate and pessimistic cost estimate are given by the cost estimate group from engineering department or finance department or contract department depending on the organization and game rules.

In summary, for Government acquisition games (DAA-AWGE), the Government optimizes the cost with the expected contractor's bidding parameters for Contractor's Sharing Ratio, $S R_{G O V_{C_{i}}{ }^{\prime}}^{O p t}$ and optimum target price, $T_{G O V_{P_{i}}}^{\mathrm{Opt}}$, as follows, from Equations (53), (54), (61) and (62):

$$
\begin{gathered}
S R_{G O V_{C_{i}}}^{O p t}=\left\{\begin{array}{c}
\frac{2(2-\alpha)}{3},\left(\frac{1}{2}\right) \leq \alpha \leq 2, \forall i ; \text { if } A_{C_{i}} \leq T_{\mathcal{C}} \\
1-\frac{4}{3} \frac{(1-\beta)\left(C_{P}-A_{C_{i}}\right)}{\left(A_{C_{i}}-T_{c}\right)} \leq \beta \leq 1 ; \forall i ; \text { if } A_{C_{i}}>T_{\mathcal{C}}
\end{array}\right\} \\
T_{G O V_{P_{i}}}^{O p t}=\left\{\begin{array}{c}
C_{P}-1.5 S R_{C U_{i}} \cdot\left(T_{\mathcal{C}}-A_{C_{i}}\right) ; \forall i ; \text { if } A_{C_{i}} \leq T_{\mathcal{C}} \\
C_{P}-1.5 .\left(1-\mathrm{SR}_{C_{C_{i}}}\right) \cdot\left(A_{C_{i}}-T_{\mathcal{C}}\right) ; \forall i ; \text { if } A_{C_{i}}>T_{\mathcal{C}}
\end{array}\right\}
\end{gathered}
$$

In practice, the contractors' bids are based on their expected profit rates based on the actual costs and expenses. Let us define the expected optimistic profit rate as $\mathrm{PR}_{\mathrm{O}}$, and the target profit rate as $P R_{T}$, one can calculate optimistic profit amount, $P F_{O_{C}}$, and target profit amount, $P F_{T_{C}}$, using the following equations:

$$
\begin{gathered}
P F_{O_{C}}=P R_{O} \cdot O_{C} \\
P F_{T_{C}}=P R_{T} \cdot T_{C}
\end{gathered}
$$

where $O_{C}$ and $T_{C}$ are the estimated optimistic cost and target cost, respectively.

Using Figure 8 and Equations (69) and (70), the non-optimum contractor sharing ratio and non-optimum target price can be estimated using the following mathematical models:

$$
\begin{gathered}
S R_{C_{i}}^{N o n}=\left\{\begin{array}{c}
\left(P F_{O_{C}}-P F_{T_{C}}\right) /\left(T_{C}-T_{C}\right) ; \forall i ; \text { if } A_{C_{i}} \leq T_{\mathcal{C}} \\
\left(C_{P}-T_{C}-P F_{T_{C}}\right) /\left(P_{C}-T_{C}\right) ; \forall i ; \text { if } A_{C_{i}}>T_{C}
\end{array}\right\} \\
T_{P_{i}}^{N o n}=\left\{T_{C}+P F_{T_{C}}\right\}
\end{gathered}
$$

where $C_{P}$ and $P_{C}$ are defined in Figure 8 as Government funding limit and price at pessimistic estimated cost, respectively.

\subsection{Mathematical and Simulation Model for Contractor Bidding Game: KTR-AWGE}

The CPIF KTR-AWGE game described in this section follows [7]. As mentioned earlier, it also assumes that the PTB solution obtained from the KTR-PWGE game model is "Type 3 Requirement" and the corresponding optimum "Contract Type" is CPIF. The objective of the KTR-AWGE model is to seek the optimum "bidding" target price and the associated contractor sharing ratios for maximum contractor profit, i.e., maximum benefit from the contractor perspective. Rewrite $P C F_{K T R_{i}}$ (Equation (49) as a function of $P C F_{G o v}$ as follow:

$$
P C F_{K T R_{i}}=C_{p}+S R_{G_{i}}\left(T_{c}-A_{C_{i}}\right)-\left(A_{C_{i}}+P C F_{G o v}\right) ; i=1,2, \ldots, N
$$


The optimization problem shown in Equation (49) becomes [4]:

$$
\left.\underset{\forall i}{\operatorname{MinMax}}\left\{F_{i}=\left(P C F_{G_{0 o v_{i}}}-P C F_{\mathrm{Gov}_{i}}^{0}\right) \cdot\left(C_{p}+S R_{G_{i}}\right)\left(T_{c}-A_{C_{i}}\right)-A_{C_{i}}-P C F_{G_{0 o v}}-P C F_{K T R_{i}}^{0}\right)\right\}, i=1,2, \ldots, N
$$

where $P C F_{G_{0 v}}, P C F_{G_{0 o v}}^{0}, C_{p}, S R_{G_{i}}, T_{\mathcal{C}}, A_{C_{i}}$ and $P C F_{K T R_{i}}^{0}$ are as defined in Section 6 above.

Again, using the calculus of variation approach, the optimum "bidding" target price, $T_{\text {Ppt }_{i}}$ is found to be [7]:

$$
T_{P_{K_{O p t_{i}}}}=\left(2 A_{C_{i}}-C_{P}\right)+2\left[P C F_{K T R_{i}}^{0}+0.5 P C F_{\text {Gov }}^{0}\right) ; i=1,2, \ldots, N
$$

The CPIF KTR-AWGE game described in this section follows [4]. It assumes that the PTB solution obtained from the KTR-PWGE game model is "Type 3 Requirement" and the corresponding optimum "Contract Type" is CPIF. The objective of the KTR-AWGE model is to seek the optimum "bidding" target price and the associated contractor sharing ratios for maximum contractor profit, i.e., maximum benefit from the contractor perspective. Rewrite $P C F_{K T R_{i}}$ (Equation (50)) as a function of $P C F_{G o v}$ as follow:

$$
P C F_{K T R_{i}}=C_{p}+S R_{G_{i}}\left(T_{c}-A_{C_{i}}\right)-\left(A_{C_{i}}+P C F_{G o v}\right) ; i=1,2, \ldots, N
$$

The optimization problem shown in Equation (49) becomes [4]:

$$
\left.\underset{\forall i}{\operatorname{MinMax}}\left\{F_{i}=\left(P C F_{G_{0 o v_{i}}}-P C F_{G o v_{i}}^{0}\right) \cdot\left(C_{p}+S R_{G_{i}}\right)\left(T_{c}-A_{C_{i}}\right)-A_{C_{i}}-P C F_{G o v_{i}}-P C F_{K T R_{i}}^{0}\right)\right\}, i=1,2, \ldots, N
$$

where $P C F_{G_{0 v} v_{i}}, P C F_{G_{0 v} i_{i}}^{0}, C_{p}, S R_{G_{i}}, T_{c}, A_{C_{i}}$ and $P C F_{K T R_{i}}^{0}$ are as defined in Section 6.2 above.

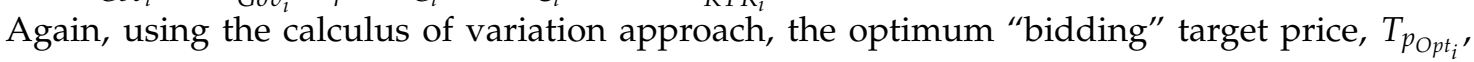
is found to be [7]:

$$
T_{p_{K_{O p t_{i}}}}=\left(2 A_{C_{i}}-C_{P}\right)+2\left[P C F_{K T R_{i}}^{0}+0.5 P C F_{\text {Gov }}^{0}\right) ; i=1,2, \ldots, N
$$

Note that for the KTR-AWGE game, the optimum win-win sharing ratio from the contractor

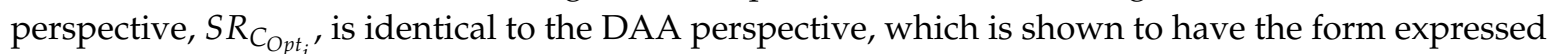
in Equation (62). As discussed earlier, the optimum contract parameters depend on the whether the contractor is under-run or over-run. The following paragraphs describe the approach to determine the optimum sharing ratios and the target price from the contractor perspective.

- $\quad$ Case 1: Under-run case: $A_{C_{i}} \leq T_{\mathcal{C}}$

For this case, we set $\alpha=2$ and the benchmark saving/profit points for the negotiation between the Government and the $i$ th contractor become [7]:

$$
\begin{gathered}
P C F_{\text {Gov }}^{0}=2\left(T_{c}-A_{C_{i}}\right) ; \forall i \\
P C F_{K T R_{i}}^{0}=\left(C_{p}-T_{c}\right)
\end{gathered}
$$

From the contractor's perspective, when $\alpha=2$ the optimum contractor sharing ratio, $S R_{C_{U K O p t_{i}}}$ is $0 \%$ (see Equation (62)) and the Government takes $100 \%$ responsibility to pay off the profit when the contractor is under-run. Thus, the optimum contractor sharing ratio and bidding target price, $T_{p_{K U O p t_{i}}}$ for this case are given by [7]:

$$
\begin{aligned}
& S R_{\text {СКОрt }_{i}}=0 ; \forall i \\
& T_{p_{\text {KUОрt }}}=C_{P} ; \forall i
\end{aligned}
$$


From the contractor perspective, the optimum price is the maximum funding limit $\left(C_{P}\right)$. Using the optimum bidding target price $T_{p K_{U O p t_{i}}}$ and sharing ratio $S R_{C_{U к O p t_{i}}}$ the optimum Government payment can be calculated from the following equation [7]:

$$
P_{\text {Gov }_{\text {UOpt }} \text { CPIF }}=A_{C_{i}}+\left(C_{P}-T_{\mathcal{C}}\right) ; \forall i
$$

- Case 2: Over-run case: $A_{C_{i}}>T_{\mathcal{C}}$

For this case, we set $\beta=1$ and the benchmark saving/profit points for the negotiation between the Government and the $i$ th contractor become [7]:

$$
\begin{gathered}
P C F_{G o v}^{0}=0 \\
P C F_{K T R_{i}}^{0}=\left(C_{p}-A_{C_{i}}\right) ; \forall i
\end{gathered}
$$

The optimum bidding target price for the over-run case, $T_{p_{\mathrm{OOpt}}}$, is found to be [4]:

$$
T_{p_{\text {KOOpt }}}=C_{P} ; \forall i
$$

Again, from the contractor perspective, the optimum price is the ceiling price. Similarly, the optimum sharing ratio, $S R_{C_{-} O K O p t_{i}}$, for the over-run case is given by [7]:

$$
S R_{\mathrm{COKOpt}_{i}}=1, \forall i
$$

This means the contractor takes $100 \%$ responsibility when it runs a cost over-run. Using the optimum bidding target price $T_{p_{K O O p t_{i}}}$ and contractor sharing ratio $S R_{C_{-} O K O p t_{i}}$, the Government payment is given by [7]:

$$
P_{\text {Gov OKOpt }_{\text {CPIF }}}=C_{P} ; \forall i
$$

The flow chart for the CPIF KTR-AWGE is similar for CPIF DAA-AWGE, which is presented in Figure 9.

In summary, for contractor bidding games (KTR-AWGE), the contractor maximizes the profits with the expected contractor's bidding parameters for contractor's sharing ratio, $S R_{C_{C_{i}}}^{O p t}$, and optimum target price, $T_{C_{P_{i}}}^{\mathrm{Opt}}$, as follows, from Equations (81), (82), (86) and (87):

$$
\begin{gathered}
S R_{C_{C_{i}}}^{O p t}=\left\{\begin{array}{c}
0, \forall i ; \text { if } A_{C_{i}} \leq T_{\mathcal{C}} \\
1 ; \forall i ; \text { if } A_{C_{i}}>T_{\mathcal{C}}
\end{array}\right\} \\
T_{C_{P_{i}}}^{O p t}=\left\{\begin{array}{c}
C_{P} ; \forall i ; \text { if } A_{C_{i}} \leq T_{\mathcal{C}} \\
C_{P} ; \forall i ; \text { if } A_{C_{i}}>T_{\mathcal{C}}
\end{array}\right\}
\end{gathered}
$$

Note that, for the non-optimum contractor bidding strategy, the non-optimum bidding sharing ratio and non-optimum target price can be estimated using the same mathematical models described in Equations (71) and (72), respectively.

\subsection{Proof of Concept: Simulation Results for CPIF Under Government's Perspective}

To illustrate the applications of the proposed models, this section provides an overview of the implementation of a NSF-funded DAA-AWGE model as shown in Figure 9 in MATLAB by the NCSU-REU (NCSU = North Carolina State University; REU = Research Experience for Undergraduate Student Team; NSF = National Science Foundation.) student team (The MATLAB model for CPIF were implemented by Brittany Dyerg (Ithaca College), Claire Goldhammerh (Washington University), Daniel Chertock (George Washington University) and Scott Mahan (Arizona State University) under 
the support of the National Science Foundation (NSF), Grant Number DMS-1461148, through the NCSU Industrial and Applied Mathematics Research Experience for Undergraduates (REU) Project during Summer 2017. The Aerospace team has been working with NCSU team to integrate CPIF model into existing MATLAB models).

The acquisition costs for the selected PTB solution are estimated by the government (DAA) and include (see Figure 7) Optimistic cost, $\mathrm{O}_{\mathrm{C}}$, target cost, $\mathrm{T}_{\mathrm{C}}$, pessimistic cost, $\mathrm{P}_{\mathrm{C}}$, and maximum funding allowable, $\mathrm{C}_{\mathrm{P}}$. The contractor's actual cost, $\mathrm{A}_{\mathrm{C}}$, is treated as a random variable either uniformly or triangularly distributed on $\left[\mathrm{O}_{\mathrm{C}}, \mathrm{P}_{\mathrm{C}}\right]$, depending on the DAA's knowledge of its cost estimates. Due to the randomness of $A_{C}$, Monte Carlo simulations are employed to find the average optimum acquisition parameters using both optimum and non-optimum contractor's bidding strategies.

- Optimal bidding: Contractors choose parameters according to the Bayesian games described above.

- Non-optimal bidding: Contractors choose parameters based on an expected profit rate described above.

For DAA-AWGE, the DAA selects a winning contractor based on the government savings for each set of contract parameters and choosing the maximize of the government saving. To average out the randomness in the optimal solutions, the acquisition and bidding models were iterated several thousand times. The CPIF DAA-AWGE program outputs the average value for each optimal contract parameter, as well as average government payment, the fee adjustment formula, and average initial conditions $P C F_{G}^{0}$ and $P C F_{K_{i}}^{0}$. This section presents simulation results of four contractors and three optimal bidders. Among the optimal bidders, the limits for the randomly generated control parameters $\alpha_{i}$ and $\beta_{i}$ are adjusted to model different bidding behavior. In this simulation, our team treats the Contractor \#1 as the "Average" bidder. The limits for Contractor \#2 are changed so that this contractor tends to select unfavorable sharing ratios from the DAA perspective; hence, Contractor \#2 is "Non-Cooperative." On the other hand, Contractor \#3 tends to select sharing ratios favorable to the DAA and is called the "Cooperative" bidder. The precise limits for these control parameters are depicted in Figure 10.

\begin{tabular}{|c|c|c|c|c|c|}
\hline Contractor Number & Behavior & Lower $\alpha$ limit & Upper $\alpha$ limit & Lower $\beta$ limit & Upper $\beta$ limit \\
\hline \hline 1 & "Average" & 1.25 & 1.25 & 0.9 & 0.99 \\
\hline 2 & "Non-cooperative" & 0.7 & 1.23 & 0.9 & 0.978 \\
\hline 3 & "Cooperative" & 1.27 & 1.8 & 0.9 & 1 \\
\hline
\end{tabular}

Figure 10. DAA-AWGE CPIF Optimal Bidder $\alpha_{i}$ and $\beta_{i}$ Limits.

Figures 11 and 12 reproduce the Graphical User Interface (GUI) for DAA-AWGE CPIF input parameters and program output, respectively. The simulation results depicting average government payments and savings as well as sharing rations are shown in Figures 13-15. Contract 3 , the "cooperative" bidder, gives the DAA more savings than the other optimal bidders despite receiving more profit (see Figure 16). Hence, it can benefit the contractor to select the sharing ratio that benefits the DAA, both in terms of profit per contract and total long-run profit.

Figure 16 shows a stark difference between the profit earned by optimal bidders and that earned by the non-optimal bidder. Figure 16a depicts that contractor 4 chooses contract parameters aggressively; the non-optimal bidding strategy demands more profit per contract but wins far less often, as shown in Figure 16c. Figure 16b shows that in the long run, the optimal bidders receive more total profit because of their higher winning percentages. Contractor four, the non-optimal bidder, would benefit from using the Nash equilibrium bidding strategy rather than aiming for a fixed profit rate. Changing the control parameter limits for the optimal bidders also affects long-run profit. Note that the "cooperative" 
contractor three demands more profit per contract than the other optimal bidders in Figure 16a but wins more contracts according to Figure $16 \mathrm{c}$. This result is feasible because the DAA and contractors are not playing a zero-sum game, that is, $P C F_{G}$ and $P C F_{K_{i}}$ do not sum to zero.

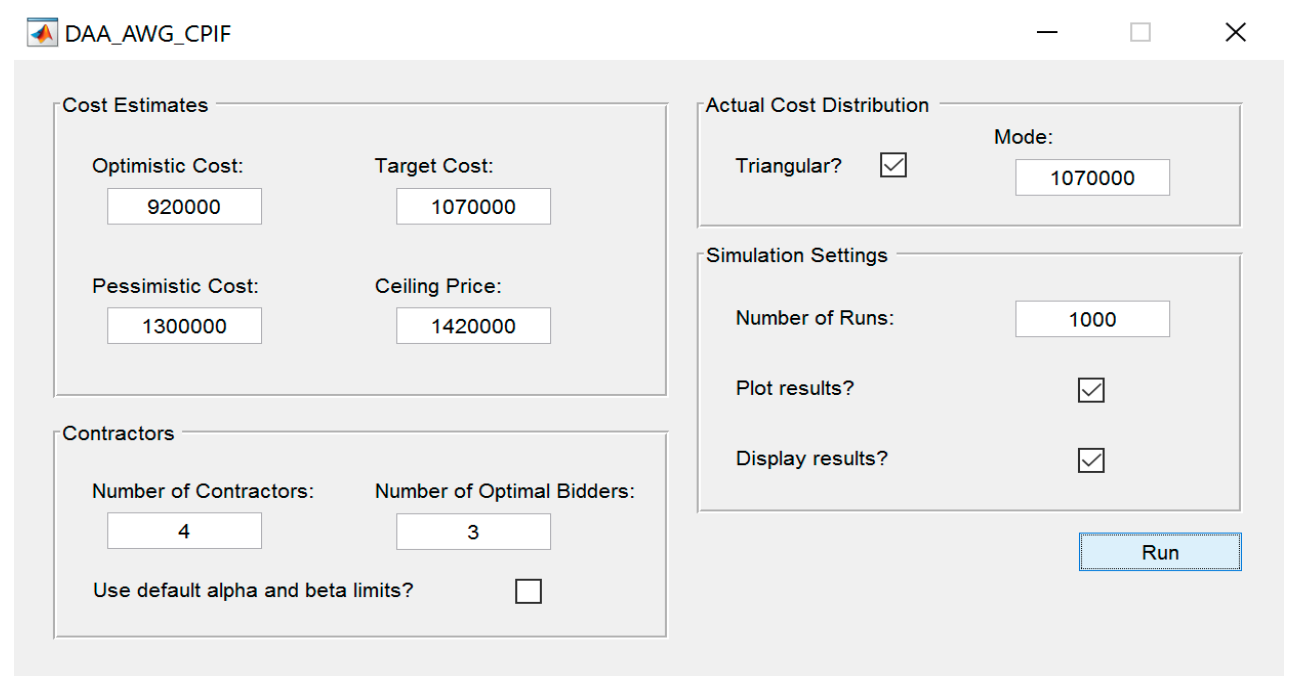

Figure 11. DAA-AWGE CPIF Input.

The average optimum target price for the under-run case is 1360912.7635.

The average optimum sharing ratio for the under-run case is 0.49353 .

The average optimum alpha parameter is 1.2767.

The optimum initial condition for government savings in the under-run case is 106774.4189.

The optimum initial condition for contractor profit in the under-run case is 350000 .

The average optimum target fee for the under-run case is 290912.7635.

The average optimum maximum fee is 364941.5759.

The adjustment formula for calculating the optimum fee for the under-run case is F_under $=0.49353^{*}(1070000-\mathrm{AC})+290912.7635$.

The average government payment for the under-run case is 1318892.4954.

The average government savings for the under-run case is 143127.7726 .

The average winning contractor profit for the under-run case is 332525.0907 .

The average optimum target price for the over-run case is 1409373.746.

The average optimum sharing ratio for the over-run case is 0.72029 .

The average optimum beta parameter is 0.97964 .

The optimum initial condition for government savings in the over-run case is 0 .

The optimum initial condition for contractor profit in the over-run case is 282138.7333.

The average optimum target fee for the over-run case is 339373.746 .

The average optimum minimum fee is 173706.8474 .

The adjustment formula for calculating the optimum fee for the over-run case is F_over $=339373.746-0.72029 *(1300000-\mathrm{AC})$.

The average government payment for the over-run case is 1416390.5226 .

The average government savings for the over-run case is -3407.2993 .

The average winning contractor profit for the over-run case is 284391.5588 .

Figure 12. CPIF DAA-AWGE Output. 

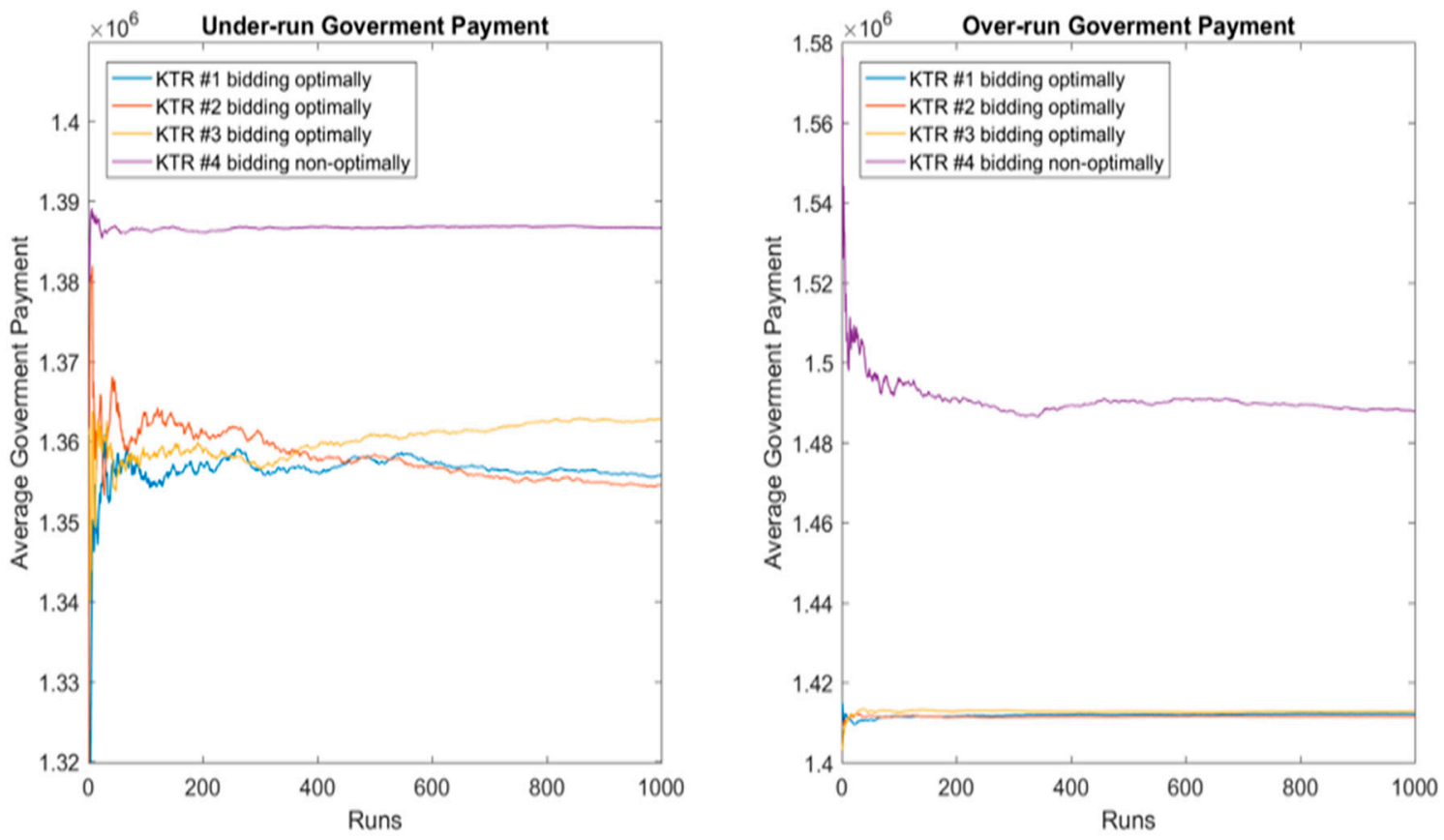

Figure 13. CPIF DAA-AWGE Average Government Payments.
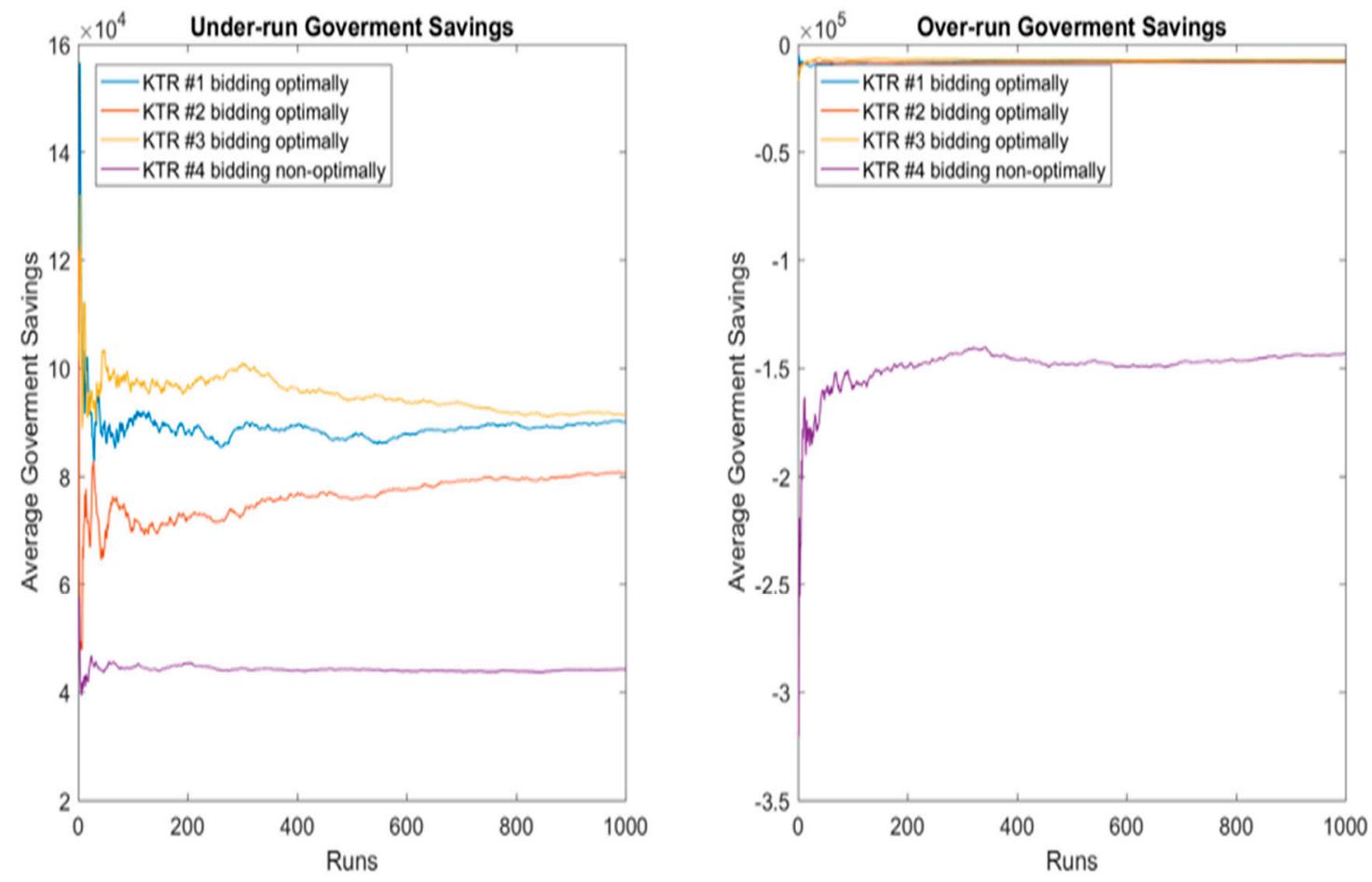

Figure 14. CPIF DAA-AWGE Average Government Savings. 

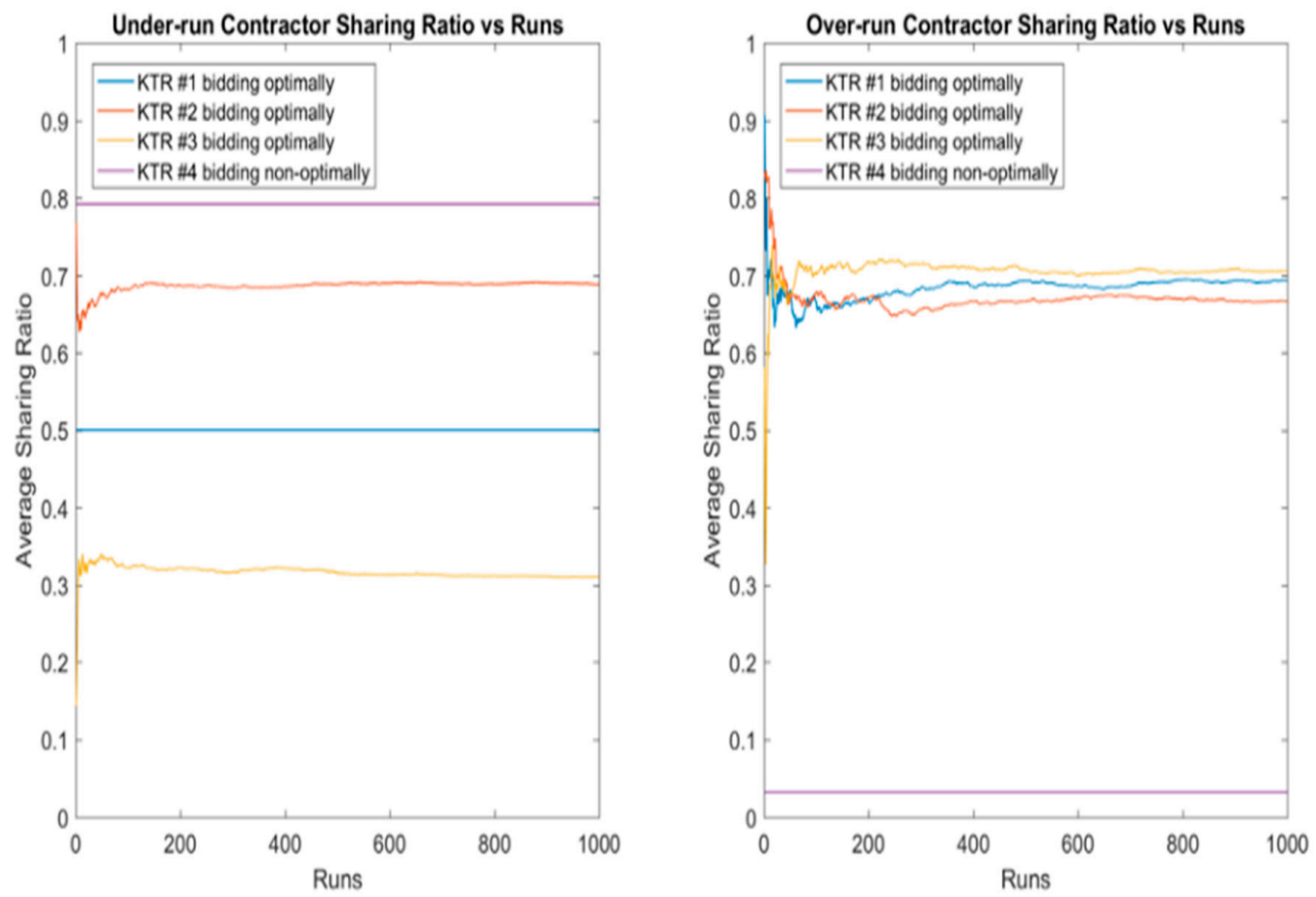

Figure 15. CPIF DAA-AWGE Average Sharing Ratios.

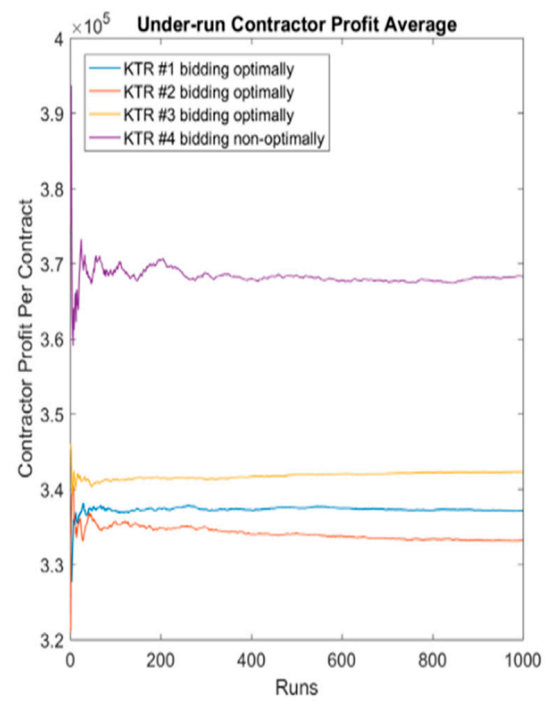

(a)

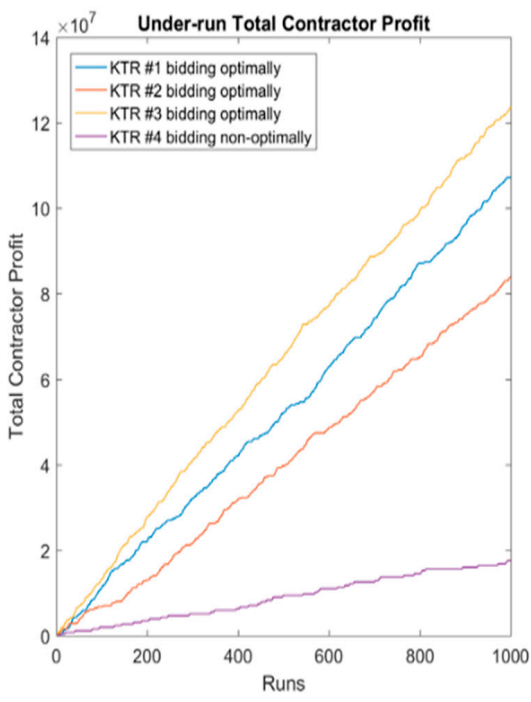

(b)

Percent Won By Each Contractor (Under-run)

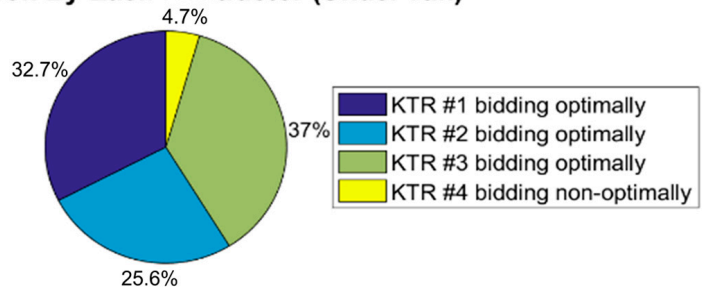

(c)

Figure 16. CPIF KTR-AWGE Simulation Results: (a) Profit per contract; (b) Total profit; (c) Winning percentages. 
Since the simulation results presented in this section are derived based on a newly proposed approach for acquiring the future DoD space systems. Since there is no baseline for our team can use to compare our results, we contend that the simulation results shown in this section are proofs of concepts of the proposed models.

\section{Discussion and Conclusions}

The objective for the development of analytical and simulation models (i.e., DAA-PWGE, DAA-AWGE, KTR-PWGE and KTR-AWGE) is to assist the Defense Acquisition Agency (DAA) to understand the contractor's perspective and to find an optimum PTB solution and a corresponding acquisition strategy that meets the objectives of both the government and that of the contractors. Thus, for a given set of requirements the government PTB solution should be optimized to maximize savings and at the same time to engage more than one contractor bidding the selected solution. This means that there will be at least two contractors that converge to the same Government's PTB solution with similar market and technology risks as predicted by the DAA-PWGE. The contract type and associated contract parameters and incentives are derived based on the compromised results obtained from the WGEs of the involved parties (DAA-AWGE and KTR-AGWE). In other word, the PTB solution will be obtained from the integrated DAA-PWGE and KTR-PWGE. The final acquisition strategy for acquiring the PTB solution obtained from the integrated DAA-PWGE and KTR-PWGE is to be generated from the integrated DAA-AWGE and KTR-AWGE. As presented in the proposed UGAF shown in Figure 3, the selection of PTB solution and acquisition strategy is a close-loop process and the PTB solution and associated contract type are converge to a single PTB solution with more than one contractor is willing to bid on it. We have shown in Section 5 that the PTB solution can be selected based on the highest payoff and cost (PCF) score with an assigned "belief" score (or probability), We plan to develop an integrated DAA-PWGE and KTR-PWGE algorithm that can be used to search for the highest PCF score and assigned "belief" score that both DAA and KTR can converge to these scores. When the KTR's PCF and "belief" scores converge to DAA's scores, the solution is straightforward. However, when the convergence is doubtful, a Decision Support Algorithm (DSA) would be needed to select the optimum PTB solution that can satisfy multiple criteria, including requirements, risks, and cost. Our team is also currently working on the development of a DSA that leveraged the work done presented in [14-19].

This paper provides an overview of the description of PTB optimization games and acquisition-bidding games from both the perspectives of the government and that of the contractors formulated through as set of analytical and simulation models. (i.e., DAA-PWGE, DAA-AWGE, KTR-PWGE and KTR-AWGE). The paper focuses on the Bayesian games under Government's perspective for acquiring a future space system using CPIF contract type, assuming that the "technical and performance risks" and "cost and schedule risks" for selected PTB solutions are "High" and "Medium" (see Figure 5), respectively. The paper also provides flow diagrams to illustrate how the combination of these models with the Monte Carlo simulation to generate (i) optimum PTB solutions that can achieve affordability from the government's perspective, and (ii) optimum CPIF contract parameters that can achieve affordability from the Government's affordability perspective and maximum profit from the contractor perspective. In addition, the paper has demonstrated how the CPIF DAA-AWGE model could be implemented in MATLAB and corresponding simulations.

Finally, our simulation results reveal how the behavior of the contractors might affect their profit level. They show that non-optimal bidders demand more profit per contract which results in a lower winning percentage and less total profit in the long run.

Therefore, it would be beneficial for contractors to implement the Nash equilibrium bidding strategy. In addition, the CPIF model further separates optimal bidders into cooperative, average, and non-cooperative strategies. The analysis suggests that contractors might select a less profitable sharing ratio, and in turn increase their long-run total profit by cooperating with the government.

The overarching goal of our proposed unified framework is to help formulate a multi-stakeholder acquisition strategy that encourages cooperative bidding leading to a win-win Nash equilibrium. 
In such a framework, we seek to change the perspectives of the players from antagonistic to collaborative. An important implication of our model is that it can serve as DAA negotiation tools to encourage cooperative bidding to increase governmental savings. As such, our unified war-gaming framework could help achieve the government's objective, one of our future research directions will be to consider the design of a web-based distributed group decision and negotiation system that would provide a seamless integration of various acquisition models in such a way that a global optimum solution can be found without negatively affecting local solutions. More importantly, our ultimate goal is to fine-tune the proposed unified model to help involved parties-contractors and various governmental agencies-continuously explore innovative solutions to meet warfighting needs in the digital age.

Acknowledgments: The authors want to express their appreciation to James Yoh, Blake Rogers and Silvia Chavarin of The Aerospace Corporation for their technical support to implement many of WGE models mentioned in this paper in MATLAB. The authors also want to thank the reviewers for their invaluable comments and constructive criticisms for improving the clarity of this paper.

Author Contributions: Tien M. Nguyen developed the frameworks and mathematical models, and wrote the key parts of the paper; Hien T. Tran worked with the REU students to improve the PTB and CPIF mathematical models and wrote Section 7.3 of the paper; Andy Guillen, Tung Bui and Sumner Matsunaga served as the sounding boards during the development of the frameworks and mathematical models, and wrote the abstract, Sections 1, 2 and 8 .

Conflicts of Interest: The authors declare no conflict of interest.

\section{References}

1. Hagel, C. The Defense Innovation Initiative (DII). Secretary of Defense 1000 Defense Pentagon; Washington, DC, USA, 2014. Available online: http://archive.defense.gov/pubs/OSD013411-14.pdf (accessed on 6 March 2018).

2. Nguyen, T.M.; Guillen, A.T.; Matsunaga, S.S.; Tran, H.T.; Bui, T.X. War-Gaming Applications for Achieving Optimum Acquisition of Future Space Systems; Simulation and Gaming; Cvetkovic, D., Ed.; InTech: London, UK, 2018; ISBN 978-953-51-5788-5.

3. Nguyen, T.M.; Guillen, A. Development of an Optimum Technical Baseline for Future Space Systems Using Advanced Game-Based Mathematical Framework-Invited Paper; SIAM-Special Session on Applied Mathematics in Industry; California State University at Fullerton: Fullerton, CA, USA, 2015.

4. Nguyen, T.M.; Guillen, A.T.; Matsunaga, S.S. A Resilient Program Technical Baseline Framework for Future Space Systems. In Proceedings of the SPIE, Baltimore, MD, USA, 22 May 2015; Volume 9469.

5. Nguyen, T.M.; Guillen, A.; Hant, J.; Kizer, J.R.; Min, I.; Siedlak, D.J.L.; Yoh, J. Owning the Program Technical Baseline for Future Space Systems Acquisition: Program Technical Baseline Tracking Tool. In Proceedings of the SPIE, Anaheim, CA, USA, 5 May 2017; Volume 10196.

6. Nguyen, T.M.; Guillen, A.T. War-Gaming Application for Future Space Systems Acquisition. In Proceedings of the SPIE, Anaheim, CA, USA, 2015; Volume 983808.

7. Nguyen, T.M.; Guillen, A. War-Gaming Application for Future Space Systems Acquisition: Part 1—Program and Technical Baseline War-Gaming Modelling Approach. In Proceedings of the SPIE, Anaheim, CA, USA, 5 May 2017; Volume 10196.

8. Nguyen, T.M.; Guillen, A.T. War-Gaming Application for Future Space Systems Acquisition: Part 2-Acquisition and Bidding War-Gaming Modelling and Simulation Approaches for FFP and FPIF. In Proceedings of the SPIE, Anaheim, CA, USA, 2017; Volume 10196.

9. Shelton, G.M.L. Report to Congressional Committees: Space Modernization Initiative (SMI) Strategy and Goals; House Armed Services Committee, U.S. House of Representatives: Washington, DC, USA, 2014.

10. Rubinstein, A. Perfect Equilibrium in a Bargaining Model. Econometrica 1982, 50, 97-109. [CrossRef]

11. Tsiropoulou, E.E.; Kapoukakis, A.; Papavassiliou, S. Energy-efficient subcarrier allocation in SC-FDMA wireless networks based on multilateral model of bargaining. In Proceedings of the IFIP Networking Conference, Brooklyn, NY, USA, 22-24 May 2013.

12. Asheim, G.B. A unique solution to n-person sequential bargaining. Games Econ. Behav. 1992, 4, 169-181. [CrossRef] 
13. Vienhage, P.; Barcomb, H.; Marshall, K.; Black, W.A.; Coons, A.; Tran, H.T.; Nguyen, T.M.; Guillen, A.T.; Yoh, J.; Kizer, J.; et al. War-Gaming Application for Future Space Systems Acquisition: MATLAB Implementation of War-Gaming Acquisition Models. In Proceedings of the SPIE, Anaheim, CA, USA, 5 May 2017; Volume 10196.

14. Bui, T.X. A Group Decision Support System for Cooperative Multiple Criteria Group Decision Making; Lecture Notes in Computer Science; Springer: Berlin, Germany; New York, NY, USA, 1987.

15. Hempsch, C.; Sebastian, H.-J.; Bui, T. Solving the Order Promising Impasse Using Multi-Criteria Decision Analysis and Negotiation; Logistics Research; Springer: Berlin/Heidelberg, Germany, 2013.

16. Bui, T.; Jarke, M. A DSS for Cooperative Multiple Criteria Group Decision Making. In Proceedings of the International Conference on Information System, New York, NY, USA, 1984; pp. 101-113.

17. Port, D.; Bui, T. Investigating Mixed Agile and Plan-Based Requirements Prioritization Strategies. 2008. Available online: https://www.researchgate.net/profile/Daniel_Port2/publication/ 268413207_Investigating_Mixed_Agile_and_Plan-based_Requirements_Prioritization_Strategies/links / 56ec37e808ae59dd41c4f7bd/Investigating-Mixed-Agile-and-Plan-based-Requirements-PrioritizationStrategies.pdf (accessed on 6 March 2018).

18. Bui, T.X.; Alexendre, G.; Sebastian, H.-J. Web Services for Negotiation and Bargaining in Electronic Markets: Design Requirements, Proof-of-Concepts, and Potential Applications to e-Procurement; Springer: Berlin, Germany, 2006.

19. Nicolella, A.J. Incentive Contracting: Contract Type Overview; Defense Acquisition University: Fort Belvoir, VA, USA, 2014.

(C) 2018 by the authors. Licensee MDPI, Basel, Switzerland. This article is an open access article distributed under the terms and conditions of the Creative Commons Attribution (CC BY) license (http:/ / creativecommons.org/licenses/by/4.0/). 